\title{
Phase 1 clinical trial for intravenous administration of mesenchymal stem cells derived from umbilical cord and placenta in patients with moderate COVID- 19 virus pneumonia: Results of Stage 1 of the study
}

Pooja Kulkarni ( $\sim$ poojakul28@gmail.com)

NeuroGen Brain and Spine Institute

\section{Alok Sharma}

LTMG Hospital: Lokmanya Tilak Municipal Medical College and General Hospital

Rohit Kulkarni

Reelabs Pvt. Ltd

Hemangi Sane

NeuroGen Brain \& Spine Institute, Stem Asia Hospital \& Research Centre: NeuroGen Brain and Spine Institute

\section{N.T. Awad}

LTMG Hospital: Lokmanya Tilak Municipal Medical College and General Hospital

Abhijit Bopardikar

Reelabs Pvt.Ltd

\section{Anagha Joshi}

LTMG Hospital: Lokmanya Tilak Municipal Medical College and General Hospital

\section{Sujata Baweja}

LTMG Hospital: Lokmanya Tilak Municipal Medical College and General Hospital

\section{Mohan Joshi}

LTMG Hospital: Lokmanya Tilak Municipal Medical College and General Hospital

Chandra Vishwanathan

Reelabs Pvt Ltd

Nandini Gokulchandran

NeuroGen Brain \& Spine Institute, Stem Asia Hospital \& Research Centre: NeuroGen Brain and Spine Institute

\section{Prerna Badhe}

NeuroGen Brain \& Spine Institute, Stem Asia Hospital \& Research Centre: NeuroGen Brain and Spine Institute

\section{Mazhar Khan}

NeuroGen Brain \& Spine Institute, Stem Asia Hospital \& Research Centre: NeuroGen Brain and Spine Institute 


\section{Amruta Paranjape}

NeuroGen Brain \& Spine Institute, Stem Asia Hospital \& Research Centre: NeuroGen Brain and Spine Institute

\section{Arjun MK}

NeuroGen Brain \& Spine Institute, Stem Asia Hospital \& Research Centre: NeuroGen Brain and Spine Institute

\section{Research Article}

Keywords: COVID-19, Mesenchymal Stem Cells, Umbilical Cord, Placenta, Cytokine Storm

Posted Date: January 31st, 2022

DOl: https://doi.org/10.21203/rs.3.rs-1279607/v1

License: (c) (i) This work is licensed under a Creative Commons Attribution 4.0 International License. Read Full License 


\section{Abstract}

Background: Mesenchymal stem cells can serve as a therapeutic option for COVID-19. Their immunomodulatory and anti-inflammatory properties can regulate the exaggerated inflammatory response and promote recovery of lung damage.

Methods: Phase-1, single-centre open-label, prospective clinical trial was conducted to evaluate the safety and efficacy of intravenous administration of mesenchymal stem cells derived from umbilical cord and placenta in moderate COVID-19. The study was done in 2 stages with total 20 patients. Herein, the results of stage 1 including first 10 patients receiving 100 million cells on day 1 and 4 with a follow up of 6 months have been discussed.

Results: No adverse events were recorded immediately after the administration of MSCs or on follow up. There was no deterioration observed in clinical, laboratory and radiological parameters. All symptoms of the study group resolved within 10 days. Levels of inflammatory biomarkers such as NLR, CRP, IL 6, ferritin and D-dimer improved in all patients after intervention along with improved oxygenation demonstrated by improvement in the SpO2 / FiO2 ratio and $\mathrm{PaO} 2$ / FiO2 ratio. None of the patients progressed to severe stage. 9 out of 10 patients were discharged within 9 days of their admission. Improvements were noted in chest $\mathrm{x}$-ray and chest CT scan scores at day 7 in most patients. No postcovid fibrosis was observed on chest CT 28 days after intervention and Chest $X$ ray after 6 months of the intervention.

Conclusion: Administration of 100 million mesenchymal stem cells in combination with standard treatment was found to be safe and resulted in prevention of the cytokine storm, halting of the disease progression and acceleration of recovery in moderate COVID-19.

Trial registration: Clinical Trial Registry- India (CTRI), CTRI/2020/08/027043. Registered on 09/08/2020 http://www.ctri.nic.in/Clinicaltrials/pdf_generate.php?

trialid=43175\&EncHid=\&modid=\&compid=\%27,\%2743175det $\% 27$

\section{Introduction}

Severe acute respiratory syndrome coronavirus 2 (SARS-CoV-2) was first identified in 2019 in Wuhan, Hubei Province, China. Due to its highly contagious nature, the World Health Organization (WHO) declared COVID-19 a global pandemic in January 2020. (1) COVID-19 spread quickly around the world and has affected millions of people so far primarily affecting the respiratory tract and lungs. The clinical spectrum of COVID-19 ranges from asymptomatic infection to critical illness. Pathophysiological studies have reported cytokine dysregulation and hyperinflammation associated with viral infection in severe and critical illness. (2) Elevated levels of pro-inflammatory cytokines result in a cytokine storm causing lung tissue edema, air exchange dysfunction, acute respiratory distress (ARDS), lung fibrosis, secondary infection, multiorgan failure often leading to death. Pre-existing comorbidities such as 
diabetes, high blood pressure, obesity, etc result in escalated complications. Mortality rate is higher in these patients who demonstrate cytokine storm. (4)

Many treatment strategies have been recommended since the diagnosis of COVID-19 and lot of research is ongoing to establish a cure for the disease. Pharmacological management for treatment of COVID-19 includes hydroxychloroquine, azithromycin, remdesivir, favipiravir, to immunomodulators e.g. steroid and IL-6 antagonists (tocilizumab, itolizumab) (5). Although, these agents showed promising results in invitro studies, the mortality rate remains high in moderate and severe COVID-19. Hence, other options are being evaluated either as drug therapy or cell therapy e.g. SARS-CoV-2 entry inhibitors, Fusion inhibitors, RdRp inhibitors, NSP-15 inhibitors, umbilical cord MSCs, etc. (6)

Due to its immunomodulatory properties, mesenchymal stem cells (MSC) have the potential to combat COVID-19 infection. In the past, MSC treatment was found to be safe and effective in various conditions such as pulmonary, orthopedic, neurologic, cardiac conditions, etc. It has also shown promise in other viral infections like Human immunodeficiency virus (HIV), hepatitis B virus, virus associated ARDS, influenza amongst others. (7-10). Patients with mild COVID-19 usually recover at home, with supportive care and isolation. Infection-hospitalization ratio is estimated to be $0.4 \%$ for individuals younger than 40 years and $9.2 \%$ for those older than 60 years. $10-20 \%$ of infected individuals progress to severe or critical stage due to cytokine storm and about $3.5 \%$ is the mortality rate. (11-12) As cytokine storm is known to be one of the major reasons associated with mortality in COVID-19, immunoregulatory agents may result in a positive outcome. (13) Therefore, we need to evaluate whether MSCs can help preventing the progression in moderate stage patients, help in faster recovery or reduce mortality.

This study was conducted to evaluate the safety and efficacy of mesenchymal stem cells derived from umbilical cord and placenta in moderate COVID-19 pneumonia. The primary endpoint of the study was to evaluate safety of the MSCs administered while the secondary endpoint was to evaluate the efficacy of these MSCs in moderate COVID-19 patients.

\section{Material And Methods}

\section{Study design and participants}

This study was a Phase 1, single-centre open label, prospective clinical trial conducted at Lokmanya Tilak Municipal General (LTMG) Hospital and Medical College, Mumbai, India in collaboration with NeuroGen Brain and Spine Institute and ReeLabs Pvt. Ltd. The study was conducted in 2 stages with total 20 patients. Stage 1 of the study including first 10 patients receiving 100 million cells has been completed with 6 months follow up. The dose was escalated to 200 million cells on day 1 and day 4 for stage 2 including next set of 10 patients which is still ongoing. Herein, the results of stage 1 with first 10 patients have been discussed. The protocol of the study was approved by the Central Drugs Standard Control Organisation (CDSCO), Ministry of Health \& Family Welfare, Government of India and the Institutional Ethics Committee of LTMG Hospital and Medical College. This clinical trial has been registered with the 
Clinical Trial Registry- India (CTRI) as CTRI/2020/08/027043. A written informed consent was obtained from all the patients and relatives before the intervention. An independent data safety and monitoring board (DSMB) was constituted to monitor any adverse events.

\section{Inclusion Criteria:}

- Patients admitted with RT-PCR confirmed COVID-19 illness.

- Age: 18-65 years without any uncontrolled co-morbidities

- Has any of the two below criteria of moderate pneumonia

(a) $\mathrm{PaO} 2 / \mathrm{FiO} 2: 200-300$

(b) Respiratory Rate $>24 / \mathrm{min}$ and $\mathrm{SaO} 2 \leq 93 \%$ on room air

\section{Exclusion Criteria:}

- Pregnant women

- Breastfeeding women

- Critically ill patients:

(a) $\mathrm{PaO} 2 / \mathrm{FiO} 2$ ratio $<200$ (ARDS)

(b) Shock (Requiring Vasopressor to maintain a MAP $\geq 65 \mathrm{mmHg}$ or MAP below 65)

- Patients with other severe co-morbidities like cancer, chronic renal, chronic liver failure and chronic cardiac failure. This will not include diabetes, hypertension, etc

- Participating in any other clinical trial

\section{Pre-Intervention Assessment:}

In stage 1 (100 million cells), 10 patients who met the inclusion and exclusion criteria were recruited in the study. All these patients underwent a detailed assessment prior to the intervention. Their medical history was recorded alongwith clinical assessment. Serological, biochemical and hematological tests which included Complete blood count, Renal function test (BUN, creatinine and GFR), Liver function test, Serum Creatine Kinase (CK), Creatine Kinase Myocardial Band (CK-MB), Troponin and myoglobin test, Serum electrolytes test, Serum HbA1Ctest, Serum Fibrinogen test, D-dimer test, Serum C-reactive protein 
test, NT-pro BNP, HIV, HCV and HBV test was conducted. Arterial blood gas analysis (ABG), Electrocardiogram (ECG) was performed along with Chest X-ray and Chest CT scan.

\section{Intervention:}

\section{Cell transplantation}

Cells used for this study were a mixture of MSCs derived from human umbilical cord blood and placenta. They were obtained from ReeLabs, Mumbai, a cGMP facility with a cord blood banking license and Form 29. The procurement and banking of these cells was done as per government guidelines. Cell culture medium used was StemProTM MSC SFM XenoFree for cell culture. All 10 patients received two doses of 100 million cells each on day 1 and day 4 along with standard treatment. Cells were suspended in $100 \mathrm{ml}$ of normal saline and were administered intravenously over forty minutes with a speed of $\sim 40$ drops per minute.

\section{Standard Treatment:}

All patients received standard medication which included antibiotics (cephalosporin, ivermectin, doxycycline), one antiviral (Lopinavir/ritonavir or Favipiravir or Remdisivir), low molecular weight heparin, methylprednisolone, vitamin supplements (vitamin E, vitamin C, zinc, multivitamins) and antacid (pantoprazole). Other medicines were administered for symptomatic relief such as paracetamol for fever, antitussive for cough, etc. Supplemental oxygen for patients who had oxygen saturation (SpO2) below $95 \%$ on room air. None of the patients received Tocilizumab.

\section{Data collection:}

Clinical parameters were measured daily by the clinical staff from Day 1 to discharge. Laboratory parameters, ABG and ECG were performed before the intervention (Day 1) followed by Day 2, 4, 6, 8 and 14. Chest X-Ray and Chest CT scan was performed on Day 1, 7, 14 and 28. Data was recorded in the case record form and electronically.

\section{Outcome measures:}

\section{Primary endpoint: Safety evaluation}

1. Avoidance of :

- Progression to severe ARDS (P/F ratio <100) 
- All-cause Mortality at 28 days

2. Oxygenation Index: SpO2

3. Multi Organ Function: CBC, LFT, Serum Creatinine, Electrolytes, troponin and myoglobin

4. Clinical measures: Fever and Respiratory Rate

5. Adverse Events occurring immediately after IV administration of MSCs (Hematoma, Local infection, Pain or Bleeding at the site of injection and Thrombophlebitis)

6. Other adverse events e.g. Pulmonary embolism, Stroke, Arrhythmias, Liver failure

\section{Secondary endpoint: Efficacy evaluation}

1. Time to symptom resolution

- Fever

$\cdot$ Cough

- Shortness of Breath

2. Duration of Hospital stay after intervention

3. Change in SOFA pre and post intervention

4. Duration of respiratory support required

- Duration of Invasive Mechanical Ventilation

- Duration of Non-Invasive Ventillation

5. Radiological improvement (Chest X Ray/Chest CT scan) at Days 7,14, 21 and 28 days after intervention.

6. Adverse events (AE) associated with intervention

7. Duration of conversion of positive to negative Covid 19 from RT PCR at Days 7,14 and 28 days after intervention.

8. Change in levels of biomarkers (CRP, IL6, Ferritin) at Days 2, 4, 6, 8, 14 days after intervention.

9. Time of Recovery on 8-point Ordinal Scale 


\section{Safety and adverse event monitoring:}

Safety monitoring was performed everyday. Progression of symptoms, laboratory parameters, vital signs and clinical assessments were monitored closely.

The adverse events monitored included.

Major: Allergic reaction, anaphylactic reaction, secondary infection, life-threatening adverse events, acute respiratory failure requiring mechanical ventilation, myocardial infarct, heart failure, Pulmonary embolism, stroke, arrhythmias, liver failure and mortality. Minor: Hematoma, local infection, pain or bleeding at the site of injection and thrombophlebitis Any adverse events if recorded were reported to the committee.

\section{Data Analysis:}

A detailed analysis was performed to study the outcome of the intervention. Neutrophil-Lymphocyte Ratio, CRP, IL-6, Ferritin, D-Dimer, Sp02/FiO2 ratio and PaO2/FiO2 ratio were analysed. Median of their values was calculated and a line graph with standard error was plotted to study the overall trend in the study population. Resolution of clinical symptoms was evaluated by calculating frequency of symptoms present on Day 1 and average number of days taken for resolution of these symptoms. Chest $X$ rays were scored subjectively based on visual assessment by an expert radiologist. $X$ - ray findings before the treatment were noted and the days at which improvement was seen and complete resolution was seen was computed and used for analysis. Comparison of Chest CT scores on Day 1, 7, 14,21 and 28 days was performed.

\section{Results}

Demographics (Table 1)

Table 1

Demographic data of the study group 


\begin{tabular}{|lll|}
\hline Total Number of patients screened & 231 \\
\hline Sample Size & & 10 \\
\hline Gender & Male & 8 \\
\hline Age & Female & 2 \\
\hline & Range & 28 to 65 Years \\
\hline Comorbidities & Mean & 47.3 years \\
\hline & Diabetes & 6 \\
\hline & Hypertension & 4 \\
\hline Follow up duration & Vitilgo & 1 \\
\hline & Past history of Tuberculosis & 1 \\
\hline & None & 3 \\
\hline
\end{tabular}

The frequency of symptoms of COVID-19 were observed in the recruited participants of this study. (Table 2)

Table 2

Frequency of symptoms of COVID-19 observed in the patients recruited for this study. 


\begin{tabular}{|lll|}
\hline Symptom & Frequency & Percentage \\
\hline Cough & 9 & 90 \\
\hline Sputum & 5 & 50 \\
\hline Shortness of breath & 10 & 100 \\
\hline Sore throat & 8 & 80 \\
\hline Chest pain & 3 & 30 \\
\hline Loss of appetite & 9 & 90 \\
\hline Loss of Taste & 6 & 60 \\
\hline Loss of Smell & 4 & 40 \\
\hline Generalized weakness/Fatigue & 9 & 90 \\
\hline Giddiness & 2 & 20 \\
\hline Headache & 2 & 20 \\
\hline Muscle aches and pains & 1 & 10 \\
\hline
\end{tabular}

\section{Primary Endpoint: Safety Evaluation}

No adverse reactions to the administration of MSCs were identified immediately after intervention or on follow up. Till day 14 , there were no negative changes in laboratory parameters such as Total White cell count (WBCs), Neutrophils, Lymphocytes, Monocytes, Eosinophils, Basophils, Hemoglobin (g/dL), Red-cell count, Platelet count, Potassium, Sodium, Serum Creatinine, BUN, GFR, Total bilirubin, Direct bilirubin, Albumin, Aspartate amino transferase, SGOT, Alanine transaminase, SGPT, Serum Creatine Kinase-MB, Serum Creatine Kinase-Total, Troponin, Myoglobin, Serum fibrinogen, NT pro BNP. No deterioration in ABG parameters were observed: $\mathrm{pH}$, Partial pressure of oxygen $(\mathrm{PaO2})(\mathrm{mmHg})$, Partial pressure of carbon dioxide (PaCO2) (mmHg), Bicarbonate (HCO3-) (mEq/L), Oxygen saturation (O2 Sat), Oxygen (Litres) $\mathrm{ABG}$, Oxygen requirement, $\mathrm{FiO} 2, \mathrm{SpO} 2 / \mathrm{FiO} 2, \mathrm{PaO} 2 / \mathrm{FiO} 2$, and likewise in ECG.

At 6 months, follow up X-rays were performed for 7 patients which did not reveal any significant abnormality. One patient had expired due to cardiac arrest after 3.5 months post intervention (unrelated to cell therapy).

\section{Secondary Endpoint: Efficacy Evaluation}

Efficacy of intervention was assessed by evaluating the time taken for COVID-19 symptoms to resolve, changes in levels of biomarkers, oxygenation and radiological findings. 


\section{Time to symptom resolution (Table 3 )}

Before completion of Day 14 , all patients were clinically stable and discharged.

Table 3

Duration of resolution of symptoms

\begin{tabular}{|l|l|}
\hline Symptoms & Average no. of days for resolution \\
\hline All symptoms & 10 \\
\hline Cough & 5 \\
\hline Sputum & 4 \\
\hline Shortness of breath & 9 \\
\hline Sore throat / Dryness & 3 \\
\hline Chest pain & 2 \\
\hline Loss of appetite & 4 \\
\hline Loss of Taste & 3 \\
\hline Loss of Smell & 4 \\
\hline Generalized weakness/Fatigue & 8 \\
\hline Giddiness & 4 \\
\hline Headache & 1 \\
\hline Muscle aches and Pain & 11 \\
\hline Requirement of supplemental oxygen & 9 \\
\hline
\end{tabular}

\section{Changes in levels of biomarkers}

\section{(A) Neutrophil-Lymphocyte Ratio}

Neutrophil-Lymphocyte ratio is a cost-effective inflammatory biomarker used to study the progression of COVID-19. Increased NLR may be indicative of excessive inflammation and immune suppression caused due to SARS-CoV-2. Median of NLR was calculated for each patient and a line graph was plotted. In the study group, NLR increased on Day 2, decreased on Day 4 and showed an increase again on Day 6. 
However, Day 6 onwards median NLR reduced consistently. Overall, a decreasing trend was observed. (Figure 1, 2)

\section{(B) C-Reactive Protein (CRP)}

The rapid clinical improvement was accompanied by decrease in inflammatory biochemical markers level. The levels of CRP decreased sharply on the second day after the administration of MSCs (Figure $3,4)$ and were maintained within the normal range of 0-6 mg/L

\section{(C) Interleukin 6 (IL6)}

The blood levels of IL-6 increased beyond the normal range of $0-7 \mathrm{pg} / \mathrm{ml}$ from Day 1 to Day 4 . The values began to reduce from Day 4 onwards and were within normal limits on Day 14. Patient 7 showed extremely high levels of IL 6 on day 1 which further increased on day 2 and gradually reduced thereafter. This change may be attributed to the immunomodulatory effect of MSCs. (Figure 5, 6) MSCs are able to increase the lymphocyte count and regulatory dendritic cells to raise their antiviral characteristic which results in the decreased level of CRP and pro-inflammatory cytokines such as IL-6 to reduce the inflammation and oxidative stress.

\section{(D) Ferritin}

The median ferritin levels were slightly higher than the normal range on Day 1 which further increased on Day 2. However, after administration of MSCs the levels of ferritin started to reduce and were found to be within normal range on Day 6. (Figure 7,8). In 4 out of 10 patients the levels showed a decreasing trend but did not normalize till Day 14. Ferritin is a key mediator of immune dysregulation, via direct immunesuppressive and pro-inflammatory effects, contributing to the cytokine storm which further results in a fatal outcome. However, as recorded in this study the median ferritin levels which were demonstrating an increasing trend started to reduce after intervention. This can be attributed to the immunomodulatory effects of MSCs.

\section{(E) D-Dimer}

The levels of D-dimer in the blood increased from Day 1 to Day 6, after which it sharply decreased and did not differ from normal values. This suggests that MSCs promote the rapid elimination of intravascular hemocoagulation, which effectively prevents microthrombosis of the lung vessels (Figure 9, 10).

\section{Improvement in markers of Oxygenation:}




\section{(A) Sp02/Fi02}

The ratio of blood oxygen saturation to the fraction of inhaled oxygen ( $\mathrm{SpO} 2$ / FiO2) is a surrogate marker of the risk of developing acute respiratory distress syndrome (ARDS). A decrease in this index may indicate risk of acute respiratory distress syndrome. In this study, administration of MSCs resulted in a rapid and effective increase in SpO2 / FiO2 demonstrating the ability of MSCs to prevent the development of ARDS and hypoxemia in COVID-19 patients and further improve oxygenation (Figure 11,12)

\section{(B) Pa02/FiO2}

$\mathrm{PaO} 2$ / FiO2 is the oxygenation index used to assess the function of oxygen exchange in lungs. It is a ratio of partial oxygen tension in arterial blood to the oxygen fraction during inspiration. A decrease in this index is an accurate marker of the threat of ARDS.

On administration of MSCs, the $\mathrm{PaO} 2$ / FiO2 increased rapidly and progressively, which indicates the ability of MSCs to significantly improve ventilation-perfusion mechanisms in patients with oxygendependent COVID-19 (Figure 13, 14).

\section{Radiological findings:}

\section{Chest X-ray}

On chest X-ray, 8 out of 10 patients showed significant bilateral lung infiltrates. 7 (87.5\%) out of these 8 patients resolved completely in average 19 days. (Figure 15)1 of these 8 had significantly improved by day 21 but did not completely resolve. No new abnormality or adverse effect of MSCs transplantation was noted in Chest radiograph 6 months post the treatment.

\section{Chest CT Scan scores}

Average CT severity score of all of the patients was 14 on Day 1 and reduced to 8 on Day 28 showing that there was significant reduction in the severity of the disease. $9 / 10$ patients showed reduction in the CT score on Day 7. All of the patients showed significant reduction in CT scores by Day 28. (Table 4) Figure 16 A-C show changes in serial CT scans.

Table 4

Radiological improvement as observed on chest CT scan scores (Patients 4 and 6 did not come to do the CT scan on Day 28) 


\begin{tabular}{|llllll|}
\hline Patient name & Pre-Intervention CT & Day 7 CT & Day 14 CT & Day 21 CT & Day 28 CT \\
\hline Patient 1 & 11 & 11 & 9 & 6 & 4 \\
\hline Patient 2 & 15 & 13 & 12 & 10 & 7 \\
\hline Patient 3 & 14 & 12 & 10 & 9 & 7 \\
\hline Patient 4 & 23 & 19 & 19 & 19 & Not done \\
\hline Patient 5 & 10 & 9 & 7 & 6 & 6 \\
\hline Patient 6 & 11 & 7 & 6 & 5 & Not done \\
\hline Patient 7 & 15 & 17 & 16 & 14 & 13 \\
\hline Patient 8 & 17 & 15 & 12 & 12 & 12 \\
\hline Patient 9 & 10 & 8 & 6 & 5 & 4 \\
\hline Patient 10 & 17 & 15 & 12 & 10 & 10 \\
\hline
\end{tabular}

\section{Discussion}

\section{Pathophysiology of SARS-CoV-2}

SARS-CoV-2 binds to ACE2 receptors to enter the target cell, where the virus replicates and subsequently infects other cells. The virus connects to ACE2 via a glycoprotein called peplomer. The lungs are the most affected as the enzyme ACE2 is abundantly present in the type II alveolar cells of the lungs. But these receptors are also present on heart, liver, kidney, intestines etc. When the virus enters the lungs, it infects the upper respiratory tract and then alveolar tissue, which may eventually progress to respiratory failure leading to death. As it enters blood circulation the virus spreads and may cause damage to other distant organs such as kidneys, heart and brain, gastrointestinal organs, liver etc. $(14,15)$ Cytokine storm and pneumonia-associated hypoxia might also contribute to liver injury or even develop into liver failure in patients with COVID-19 who are critically ill. (16)

\section{Cytokine storm in COVID-19}

It has been reported that, dysregulated cytokine/chemokine responses and higher virus titers cause an inflammatory cytokine storm with lung immunopathological injury in COVID-19. Such Inflammation associated with the cytokine storm may begin at one local site and further spread throughout the body via the systemic circulation. (17) Similarly, infected patients have shown increased plasma concentrations of inflammatory cytokines, including interleukins (IL) 2, 6, 7, and 10, granulocyte-colony stimulating factor (G-CSF), monocyte chemoattractant protein 1 (MCP1), macrophage inflammatory protein 1 alpha (MIP1A), interferon-囚-inducible protein 10 (IP10)and TNF-a. (18) 
Large amount of inflammatory cell infiltrations have been observed in lungs from severe COVID-19 patients, these aberrant pathogenic Th1 cells and inflammatory monocytes may enter the pulmonary circulation in huge numbers and play an immune damaging role to cause lung functional disability and quick mortality. In a study including 41 patients with COVID-19, Huang, et. al. demonstrated a cytokine profile that was like that of secondary hemophagocytic lymphohistiocytosis (sHLH), a hyper inflammatory condition triggered by viral infection (19). The patients admitted in the ICU showed higher levels of granulocyte-macrophage colony-stimulating factor (GM-CSF), interferon gamma-induced protein 10 (IP10), monocyte chemoattractant protein-1 (MCP-1), macrophage inflammatory protein 1 alpha (MIP1A), and tumor necrosis factor alpha (TNFa). The role of a hyperinflammatory response underlying development of severe and critical illness was confirmed in another study by higher serum levels of Creactive protein (CRP), interleukin-6 (IL-6) and Ferritin in patients that had died. (20) The dysregulated immune response results in endothelial injury and formation of micro and macro blood clots which together with pulmonary inflammation led to a diffuse alveolar damage, fibrin exudates and fibrotic healing in the lungs which further compromises the oxygen absorption causing oxygenation failure and acute respiratory distress syndrome (ARDS). This may also result in secondary pulmonary infections such as bacterial pneumonia. (21) Prevention or attenuation of cytokine storm is therefore crucial to lower COVID-19-induced mortality.

There are no approved treatments for Covid-19 but some medications including antiviral, antiinflammatory have shown to be beneficial. There is an urgent need to explore treatment strategies that can prevent patients from worsening clinically and progressing to severe or critical stage. Due to its immunomodulatory properties, cell therapy has a potential to halt the progression of the disease and accelerate the recovery process.

To evaluate the safety and efficacy of cell therapy in COVID-19, we administered 10 patients with moderate illness with a mixture of 100 million MSCs derived from umbilical cord and placenta.

Rationale for use of MSCs derived from umbilical cord and placenta

Cellular therapy has been studied widely for treating various conditions, including pulmonary, immunological, haematological, cardiac, neurological, hepatic, endocrine, musculoskeletal, skin, and ophthalmological diseases. (22-28) Various clinical studies have demonstrated the safety and efficacy of umbilical cord and placental MSCs individually. (29-34) For this study, a mixture of umbilical cord and placenta derived MSCs was used since, a mixture results in an enhanced outcome combining the benefits of both types of cells. Invitro studies have shown that this mixture of cells secretes increased concentration of paracrine molecules such as IGF-1, KGF, VEGF, SDF-1a as compared to individual cell types which are responsible for stimulating lung repair, angiogenesis, stem cell recruitment, etc. Acute toxicity, chronic toxicity, genotoxicity, immunotoxicity, tumoregenic potential studies conducted for this mixture of cells showed that it was non-toxic, non- mutagenic, non-tumorogenic and had no immunotoxic effect on the organs of the immune system, and the cell parameters of peripheral blood and bone marrow. These cells are safe, effective and are easily available without any ethical barriers. 


\section{Immunomodulatory (paracrine) effects of MSCs counteracting the cytokine storm:}

Umbilical cord cells also attenuate lung inflammation by a multitude of paracrine functions, including enhanced interleukin (IL)-10 expression and modulation via prostaglandin-E2 (PGE2), GM-CSF, IL-6 and IL-13. (35) Both umbilical cord and placenta derived stem cells secrete paracrine factors, including human angiopoietin-1 (Ang-1), Hepatocyte Growth Factor (HGF), insulin-like growth factor I (IGF-I), prostaglandin E2 (PGE2), transforming growth factor beta 1 (TGF- $\beta 1$ ), vascular cell adhesion protein 1 (VCAM-1) and Vascular Endothelial Growth Factor (VEGF), in varying levels. Although they have different growth dynamics, stem derived cells show the highest secretion of Ang-1 and VEGF and the lowest secretion of TGF- $\beta 1$, while umbilical cord derived cells show the highest secretion of IGF-I, PGE2 and TGF- $\beta 1$, HGF and VCAM-1. (36)

Leng et al. 2020 have also demonstrated that anti-inflammatory and trophic factors like Transforming Growth Factor (TGF)- $\beta$, HGF, VEGF, Leukaemia Inhibiting Factor (LIF), Galanin (GAL), Nitric Oxide Associated protein 1 (NOA1), Fibroblast Growth Factor (FGF), Epidermal Growth Factor (EGF), Brainderived Neurotrophic Factor (BDNF), and Nerve Growth Factor (NGF) are highly expressed in mesenchymal stem cells, further bolstering their immunomodulatory role. (37)

\section{Differentiation of MSCs into AT2 cells and their immunity towards COVID-19:}

The COVID-19 causing novel coronavirus 2019-nCoV uses the angiotensin converting enzyme II (ACE2) and Transmembrane Serine Protease 2 (TMPRSS2) receptor to enter host cells. (38) ACE2 is enriched in human alveolar cells (39) and TMPRSS2 is a known human airway and alveolar protease. (40) This may explain the rapid infection rate observed worldwide. It is shown that mesenchymal stem cells are ACE2 and TMPRSS negative, which indicates that these cells may not be susceptible to COVID-19. (37)

Surface Protein (SP) A and $C$ are highly expressed in umbilical mesenchymal stem cells, indicating that these might differentiate to alveolar epithelial (AT2) cells. (37) These cells have also been shown to differentiate into a variety of alveolar cells and integrate into target tissue in rodent models. $(35,41)$ The human placenta also enriches mesenchymal stem cells, which are multipotent progenitors. (42)

\section{Antiviral effects of MSCs:}

MSCs transplantation has shown significantly reduced mortality in H7N9 induced ARDS. (43) In severe influenza, MSCs' can tackle inflammatory cytokine excess that leads to acute lung injury induced due to H5N1 infection. (44) MSCs also regulate inflammatory responses, improve alveolar fluid clearance, and maintain lung epithelial and endothelial integrity. $(45,46)$ Moreover, KEGG pathway analysis has shown 
that these cells are closely involved in the antiviral pathways, specifically those related to Epstein-Barr, Hepatitis B, viral carcinogenesis and human T-cell leukaemia virus 1 infection. (47) They have also been implicated in several other pathways, namely herpes viral infections via the cGAS-STING pathway (48), Japanese encephalitis via up-regulation multiple pro-survival pathways (49), and a non-canonical PI3KNFKBpathway against latent HIV-1. (50)

\section{Anti-inflammatory and immune regulatory ability:}

MSCs have shown to induce immunomodulation primarily through paracrine signaling, stimulation of secretion of anti-inflammatory molecules such as Interleukin (IL)-10. Also, they increase the lymphocyte count thereby increasing their antiviral characteristic which in turn results in decreased C-reactive protein and pro-inflammatory cytokines including IL-6, TNFa, IL-8, etc. Studies have shown that the antiinflammatory ability of MSCs can attenuate virus-induced lung injury and death in mice. $(51,52)$ These cells also have a known safety and efficacy profile in ARDS, chronic obstructive pulmonary disease (COPD), idiopathic pulmonary fibrosis (IPF), obstructive bronchiolitis (OB) and bronchopulmonary dysplasia. Cell therapy using MSCs has therefore been proposed as a suitable treatment approach and several clinical trials have begun.

The immune modulating action of stem cells is mediated by TLRs (TLR, mainly TLR3 and TLR4) present on the surface of MSCs. RNA viruses [act as Pathogen-associated molecular pattern (PAMP)] activate these TLRs, which leads to secretion of certain chemokines like MIP-1a and MIP-1 $\beta$, RANTES, CXCL9, CXCL10, and CXCL11 etc, which leads to an anti-inflammatory response. (53) This response may be useful against the hyperimmune response/ cytokine storm observed in COVID-19. There has been hypersecretion of pro-inflammatory cytokines which includes IL-2, IL-6, IL-7, G-CSF, IP10, MCP1, MIP1A and TNFa which influences MSCs to release anti-inflammatory molecules (IL-10) with the release of soluble factors like transforming growth factor- $\beta 1$ (TGF- $\beta 1$ ) prostaglandin E2 (PGE2), hepatocyte growth factor (HGF), indoleamine-pyrrole 2,3- dioxygenase (IDO), and nitric oxide (NO). (54) These in turn decrease the proliferation of activated T-cells and NO on the other hand causes cell cycle arrest by repressing the phosphorylation of signal transducers and transcription of STAT-5 in T-cells. Further, IDO secretion by MSCs leads to apoptosis of activated T-cells and converts tryptophan into kynurenine causing suppression of proliferation of effector T-cells. (55)

\section{Regeneration and repair:}

The abnormal immune response in SARS-CoV-2 infection leads to acute and chronic lung injury often involving fibrosis either as a cause or consequence. MSCs promote repair through paracrine signaling inducing secretion of growth factors such as Hepatocyte Growth Factor (HGF), transforming growth factor beta 1 (TGF- $\beta 1$ ), Vascular Endothelial Growth Factor (VEGF) etc. which are necessary for tissue repair. Through their regenerative and reparative potential, they may protect alveolar epithelial cells, bring about recovery of pulmonary microenvironment, improve lung dysfunction and pulmonary fibrosis. 
Multiple pro-survival pathways converge and death-inducing pathways are attenuated on a cellular level to bring about improvements in the lungs. Inhibition of pulmonary fibrosis and reduced collagen deposition by these cells (56-58) may lead to decreased edema and opacity in chest X-rays. Further, MSCs trapped in pulmonary circulation undergo differentiation over the long term to yield a multitude of alveolar cell types that integrate into the pulmonary tissue and improve lung function; $(41,59)$ we may thus also expect improved tissue microarchitechture in the chest CT scans along with improved air exchange and lung function.

\section{Antimicrobial properties}

Along with immunomodulation and regeneration, MSCs also possess antimicrobial properties. Besides, these cells have shown to be ACE-2 negative and therefore cannot be infected by SARS-CoV-2. (60)

\section{Angiogenesis}

VEGF secreted by stem cells is a pro-angiogenic factor. Angiogenesis is critical for tissue regeneration. (61) In the lung, angiogenesis is crucial since the blood-air interface is the source of oxygenation and oxygen delivery to the body. Through secretion of VEGF, stem cells can help recovery from lung injury. Animal studies have shown that administration of VEGF improved aeration and prevented the development of respiratory distress syndrome and mortality in premature animals. (62)

\section{Rationale for Intravenous injection}

Safety and efficacy have been satisfactorily demonstrated in the intravenous administration of these cells in the human body for all the conditions mentioned above at different doses, reviewed exhaustively by Can et al. (22) Intravenous route of administration is considered to be an ideal approach given its broad biodistribution and easy access. It has been used as the route of cell delivery for a large number of preclinical and clinical studies. The first organ through which intravenously injected MSCs pass are the lungs. (63) Engraftment in the lungs is a very rapid event, cells can be detected already seconds or minutes after intravenous transplantation. $(64,65)$ Cell fate tracking studies in sheep $(66,67)$ and rats $(68,69)$ have shown the superiority of the intravenous route for administering these cells, with the cells primarily distributed in the lungs. Studies have shown that the detainment of MSCs in the lungs is due to the combination of mechanical and physiological conditions and may be due to the small capillary size, the large capillary network and the strong adhesion properties of MSC. Cultured MSCs are more than 20 $\mu \mathrm{m}$ in diameter, which does not allow them to pass through the lungs as they are larger than the width of the micro-capillaries of the lungs. (70) These cells thus may improve the pulmonary microenvironment and lung function by differentiating into different types of alveolar epithelial cells as well as immunomodulation, are safely tolerated, and efficacious in improving tissue microarchitecture. These 
data taken together rationalize the intravenous administration of umbilical cord and placenta mesenchymal stem cells for the treatment of COVID-19

\section{Clinical Evidence}

The first study was conducted in China by Leng, et al to assess if cell therapy using MSC could improve outcome of patients with COVID-19. 7 patients, including 1 critically ill, 4 severe and 2 non-severe cases, received a single dose of MSCs ( $1 \times 106$ cells/kg body weight) by IV infusion; 3 severe cases forming the control group received placebo. Significant improvement in pulmonary function was noted in all patients in the MSC treatment group within 2 days. There were no MSC infusion associated adverse events. Two non-severe and one severe patient were discharged within 10 days following recovery. As compared to the control group, pro-inflammatory TNF-a significantly decreased while the anti-inflammatory IL-10 levels increased in the MSC treatment group. (37)

Another study including 31 patients with severe COVID-19 pneumonia demonstrated improved clinical outcomes following IV infusion of human umbilical cord-derived MSC (hUC-MSC) in a dose of $1 \times 106$ cells/kilogram of weight (71). The SARS-CoV-2 PCR test results turned negative in a mean time of 10.7 (4.2) days. Clinical data and laboratory parameters showed that UC-MSC therapy improved oxygenation and attenuated the hyper-inflammatory state in these patients.

Multiple case reports showing benefit of hUC-MSCs in patients with Covid 19 have been published. No adverse events were reported. Patients showed improved symptoms alongwith improved inflammatory markers. (72-74)

Sengupta et al. conducted a prospective non-randomized open-label cohort study using exosomes derived from allogenic BMMSCs in 24 confirmed COVID-19 patients. $83 \%$ survival rate was observed with a recovery rate of $71 \%(17 / 24)$, stability in $13 \%(3 / 24)$ and mortality unrelated to treatment was $16 \%$ (4/24). Laboratory investigations showed significant reduction in absolute neutrophil count with alleviated levels of acute phase reactants, C-reactive protein, downregulating cytokine storm and restoring immunity. (75)

Another cell-based therapy, derived from allogenic cardiospheres was assessed for its safety and effectiveness in 6 critically ill COVID-19 patients by Singh et al. All patients were on ventilatory support. All patients survived with 4 discharged and 1 on respiratory support compared to $18 \%$ mortality in control group. Results were well correlated with diminished levels of ferritin and absolute lymphocyte counts, suggesting the role of cell-based therapies in modifying the immune responses. (76)

\section{Clinical outcome of this study}

Use of MSCs significantly decreased the time required for COVID-19 symptoms to resolve. (Table 2). 
It has been reported that the median duration for symptom resolution of Covid 19 patients is 16 days, (77) however, we noticed that all symptoms of our study group resolved within 10 days. Cough, sore throat, sputum, chest pain, loss of appetite, taste and smell, giddiness, resolved within 5 days. However, generalized fatigue, shortness of breath and requirement for supplemental oxygen was resolved within 10 days. 9 out of 10 patients were discharged within 9 days of their admission. Along with improved clinical symptoms, levels of inflammatory biomarkers such as C-reactive protein, interleukin 6, ferritin and Ddimer also improved in all patients after intervention. There was no deterioration observed in clinical and laboratory parameters. None of the patients progressed to severe stage of Covid. Improved oxygenation was recorded in all the patients which was demonstrated by improvement in the SpO2 / FiO2 ratio and $\mathrm{PaO} 2$ / FiO2 ratio. None of the patients showed any major or minor adverse events immediately after intervention or on follow up after 6 months. One patient with history of diabetes mellitus expired due to cardiac arrest after 3.5 months post intervention which was unrelated to cell therapy. Cardiac manifestations have been reported in patients recovering after COVID-19. (78) While patients with preexisting cardiovascular disease and risk factors are more likely to experience cardiac sequelae, those with no cardiovascular history have also shown signs of cardiac complications because of COVID-19. Mechanisms responsible for cardiovascular sequelae in post COVID-19 may include direct viral invasion, downregulation of ACE2, inflammation and the immunologic response affecting the structural integrity of the myocardium, pericardium and conduction system. (79)

Consistent decline in disease severity within a short duration alongwith normalization of oxygen saturation can be attributed to the anti-inflammatory, immunomodulatory, angiogenic and anti-viral effects of MSCs. Administration of MSCs in moderate stage Covid patients resulted in prevention of the cytokine storm and halting the disease progression.

\section{Radiological findings}

Radiological investigations like Chest X-ray and Chest CT scan showed no adverse effects of the MSCs transplantation on lung tissue. In addition, no post-covid fibrosis was observed on Chest CT post 28 days of the treatment and Chest $X$ ray post 6 months of the treatment.

On chest X-ray, 8 out of 10 patients showed significant bilateral lung infiltrates. 7 (87.5\%) out of these 8 patients resolved completely in average 19 days. Improvement was noted in the radiographs at Day 7 in most patients. Warissara Kiththiworaphongkich, 2021 showed that the improvement was seen in X-rays post 13 days of the illness. (80) However, in this study improvement was seen post 7 days of treatment suggesting early resolution of lung pathology.

Temporal changes in the lung tissue involvement studied previously on a CT scan shows that CT scores peak during illness days $6-11$. $(81,82)$ In this study, $90 \%$ of the patients receiving MSCs transplantation showed reduction in the CT score at day 7 and the scores continued to reduce thereafter, suggesting better resolution of lung pathology post treatment. 


\section{Conclusion}

Stage 1 of this phase 1 clinical trial wherein 10 patients with moderate COVID-19 infection were administered two doses of MSCs (100 million cells each on Day 1 and Day 4) was found to be safe and effective. No adverse events were noted. Early resolution of symptoms, improved inflammatory markers, improved oxygenation and halting of disease progression observed in the study population after intervention, can be attributed to the ability of MSCs to immunomodulate, reduce inflammation, prevent cytokine storm, promote angiogenesis, improve oxidative stress and oxygenation in moderate COVID-19. The combination of MSCs derived from umbilical cord and placenta with standard treatment may be further explored as an effective therapeutic strategy for COVID-19. The regenerative and repair potential of these cells may also help in better post Covid recovery.

\section{Abbreviations}

1. SARS-CoV-2-Severe acute respiratory syndrome coronavirus 2

2. IL-6-Interleukin 6

3. MSCs-mesenchymal stem cells

4. ARDS- Acute respiratory distress

5. BUN-blood urea nitrogen

6. GFR-glomerular filtration rate

7. LFT-Liver function test,

8. CK-Serum Creatine Kinase

9. CK-MB-Creatine Kinase Myocardial Band

10. NT-pro BNP- N-terminal pro b-type natriuretic peptide

11. HIV-human immunodeficiency virus

12. HCV- Hepatitis C Virus

13. HBV-Hepatitis B Virus

14. ABG- Arterial blood gas analysis

15. ECG-Electrocardiogram

16. CBC- complete blood count

17. Sp02- Oxygen saturation

18. PaO2- Partial pressure of oxygen

19. FiO2-fraction of inspired oxygen

20. NLR- Neutrophil-Lymphocyte ratio

21. ACE2- angiotensin converting enzyme II

22. G-CSF-granulocyte-colony stimulating factor

23. MCP1-monocyte chemoattractant protein 1 
24. MIP1A-macrophage inflammatory protein 1 alpha

25. IP10-interferon-囚-inducible protein 10

26. TNF-a-tumor necrosis factor alpha

27. KGF

28. SDF-1a

29. IL-10-interleukin-10

30. PGE2-prostaglandin-E2

31. GM-CSF-

32. IL-13- interleukin-13

33. Ang-1-human angiopoietin-1

34. HGF- Hepatocyte Growth Factor

35. IGF-I - insulin-like growth factor I

36. PGE2- prostaglandin E2

37. TGF- $\beta 1$-transforming growth factor beta 1

38. VCAM-1-vascular cell adhesion protein 1

39. VEGF-Vascular Endothelial Growth Factor

40. LIF-Leukaemia Inhibiting Factor

41. GAL- Galanin

42. NOA1-Nitric Oxide Associated protein 1

43. FGF -Fibroblast Growth Factor

44. EGF- Epidermal Growth Factor

45. BDNF-Brain-derived Neurotrophic Factor

46. NGF- Nerve Growth Factor

47. TMPRSS2-Transmembrane Serine Protease 2

48. hUC-MSC-human umbilical cord-derived MSC

49. PCR- polymerase chain reaction

\section{Declarations}

\section{Data Availability Statement:}

The datasets used and/or analysed during the current study are available from the corresponding author on reasonable request.

\section{Competing Interests:}


The authors declare that they have no competing interests

\section{Ethics approval}

Institutional Ethics Committee of LTMG Hospital and Medical College

\section{Consent to participate}

Not applicable

\section{Funding:}

NeuroGen Brain and Spine Institute: Research department of NeuroGen Brain and Spine Institute participated in analysis, and interpretation of data and in writing the manuscript.

\section{ReeLabs Pvt. Ltd:}

Cells were obtained from ReeLabs Pvt. Ltd

\section{Acknowledgement:}

Not Applicable

\section{Author Contribution:}

AS, the conception and design of the study, final approval of the version to be submitted

RK, the conception and design of the study, final approval of the version to be submitted

HS, design of the study, Interpretation of data, revising article critically for important intellectual content

NTA, final approval of the version to be submitted

$A B$, the conception and design of the study, final approval of the version to be submitted

AJ, acquisition of data and interpretation of data, final approval of the version to be submitted

SB, the conception and design of the study, final approval of the version to be submitted

MJ, final approval of the version to be submitted 
$\mathrm{CV}$, the conception and design of the study

NG, revising article critically for important intellectual content

$\mathrm{PB}$, revising article critically for important intellectual content

MK, acquisition of data

AP, acquisition of data, analysis and interpretation of data, drafting the article

PK, acquisition of data, analysis and interpretation of data, drafting the article

AMK, acquisition of data

All authors have read and approved the manuscript.

\section{References}

1. Zhu H, Wei L, Niu P. The novel coronavirus outbreak in Wuhan, China. Glob health res policy 2020;5,6.

2. García LF. Immune response, inflammation, and the clinical spectrum of COVID-19. Frontiers in immunology. 2020;11:1441.

3. Wu C, Chen X, Cai Y, Zhou X, Xu S, Huang H, Zhang L, Zhou X, Du C, Zhang Y, Song J. Risk factors associated with acute respiratory distress syndrome and death in patients with coronavirus disease 2019 pneumonia in Wuhan, China. JAMA internal medicine. 2020;180(7):934-43.

4. Fajgenbaum DC, June CH. Cytokine storm. New England Journal of Medicine. 2020;383(23):2255-73.

5. Sanders JM, Monogue ML, Jodlowski TZ, Cutrell JB. Pharmacologic treatments for coronavirus disease 2019 (COVID-19): a review. JAMA. 2020;323(18):1824-36.

6. Mahalmani VM, Mahendru D, Semwal A, Kaur S, Kaur H, Sarma P. COVID-19 pandemic: a review based on current evidence. Indian J. Pharmacol. 2020;1:117. 52.

7. Gupta RK, Peppa D, Hill AL, Gálvez C, Salgado M, Pace M, McCoy LE, Griffith SA, Thornhill J, Alrubayyi A, Huyveneers LE. Evidence for HIV-1 cure after CCR5 $\Delta 32 / \Delta 32$ allogeneic haemopoietic stem-cell transplantation 30 months post analytical treatment interruption: a case report. The Lancet HIV. 2020;7(5):e340-7.

8. Peng L., Xie D., Lin B.-L., Liu J., Zhu H., Xie C. Autologous bone marrow mesenchymal stem cell transplantation in liver failure patients caused by hepatitis B: short-term and long-term outcomes. Hepatol. Baltim. Md. 2011;2:820-828. 54.

9. Xiao K., Hou F., Huang X., Li B., Qian Z.R., Xie L. Mesenchymal stem cells: current clinical progress in ARDS and COVID-19. Stem Cell Res. Ther. 2020;22:305. 11. 
10. Du J., Li H., Lian J., Zhu X., Qiao L., Lin J. Stem cell therapy: a potential approach for treatment of influenza virus and coronavirus-induced acute lung injury. Stem Cell Res. Ther. 2020;24:192. 11

11. Gates B. Responding to Covid-19-a once-in-a-century pandemic?. New England Journal of Medicine. 2020;382(18):1677-9.

12. Wang $Y$, Wang Y, Chen $Y$, Qin Q. Unique epidemiological and clinical features of the emerging 2019 novel coronavirus pneumonia (COVID-19) implicate special control measures. Journal of medical virology. 2020;92(6):568-76.

13. Tay MZ, Poh CM, Rénia L, MacAry PA, Ng LF. The trinity of COVID-19: immunity, inflammation and intervention. Nature Reviews Immunology. 2020;20(6):363-74.

14. Walls AC, Park JY, Tortorici AM, Wall A, McGuire TA, Veesler D. Structure, function, and antigenicity of the SARS-CoV-2 spike glycoprotein. Cell. 2020; 181:281-92.e6.

15. Shang J, Ye G, Shi K, Wan Y, Luo C, Aihara H, et al. Structural basis of receptor recognition by SARSCoV-2. Nature. 2020; 581:221-4

16. Ghoda A, Ghoda M. Liver Injury in COVID-19 Infection: A Systematic Review. Cureus. 2020;12(7):e9487

17. Tisoncik JR, Korth MJ, Simmons CP, Farrar J, Martin TR, Katze MG. Into the eye of the cytokine storm. Microbiol Mol Biol Rev. 2012;76(1):16-32.

18. Melo AK, Milby KM, Caparroz AL, Pinto AC, Santos RR, Rocha AP, Ferreira GA, Souza VA, Valadares LD, Vieira RM, Pileggi GS. Biomarkers of cytokine storm as red flags for severe and fatal COVID-19 cases: A living systematic review and meta-analysis. PloS one. 2021;16(6):e0253894.

19. Huang C, Wang Y, Li X, Ren L, Zhao J, Hu Y, Zhang L, Fan G, Xu J, Gu X, et al. Clinical features of patients infected with 2019 novel coronavirus in Wuhan, China. Lancet. 2020;395(10223):497-506.

20. Chen N, Zhou M, Dong X, Qu J, Gong F, Han Y, Qiu Y, Wang J, Liu Y, Wei Y, et al. Epidemiological and clinical characteristics of 99 cases of 2019 novel coronavirus pneumonia in Wuhan, China: a descriptive study. Lancet. 2020;395(10223):507-13.

21. Matthay MA, Zemans RL, Zimmerman GA, Arabi YM, Beitler JR, Mercat A, Herridge M, Randolph AG, Calfee CS. Acute respiratory distress syndrome. Nat Rev Dis Primers. 2019;5(1):18.

22. Can A, Celikkan FT, Cinar O. Umbilical cord mesenchymal stromal cell transplantations: A systemic analysis of clinical trials. Cytotherapy. 2017;19(12):1351-82.

23. Sharma A, Gokulchandran N, Sane H, Nagrajan A, Paranjape A, Kulkarni P, Shetty A, Mishra P, Kali M, $\mathrm{Biju} \mathrm{H}$, Badhe P. Autologous bone marrow mononuclear cell therapy for autism: an open label proof of concept study. Stem cells international. 2013;2013. Article ID 623875, 13 pages.

24. Tsilimigras DI, Oikonomou EK, Moris D, Schizas D, Economopoulos KP, Mylonas KS. Stem Cell Therapy for Congenital Heart Disease: A Systematic Review. Circulation. 2017;136(24):2373-2385.

25. Sharma A, Sane H, Gokulchandran N, Kulkarni P, Gandhi S, Sundaram J, Paranjape A, Shetty A, Bhagawanani K, Biju $\mathrm{H}$ and Badhe P. A clinical study of autologous bone marrow mononuclear cells 
for cerebral palsy patients: a new frontier. Stem Cells International, Volume 2015, Article ID 905874, 11 pages

26. Sharma A, Sane H, Gokulchandran N, Gandhi S, Bhovad P, Khopkar D, Paranjape A, Bhagwanani K, Badhe $P$. The role of cell therapy in modifying the course of limb girdle muscular dystrophy- $A$ Longitudinal 5-year study. Degenerative Neurological and Neuromuscular Disease 2015:5 93-102

27. Zhang J, Lv S, Liu X, Song B, Shi L. Umbilical Cord Mesenchymal Stem Cell Treatment for Crohn's Disease: A Randomized Controlled Clinical Trial. Gut Liver. 2018;12(1):73-78.

28. Sharma A., Sane H., Paranjape A., Varghese R., Nair V., Biju H., Sawant D., Gokulchandran N., Badhe P. Improved survival in Amyotrophic Lateral Sclerosis patients following Autologous Bone Marrow Mononuclear Cell Therapy: A Long term 10-year retrospective study, Journal of Neurorestoratology, 2021, 9(2): 117-136

29. Torre P de la, Pérez-Lorenzo MJ, Flores Al. Human Placenta-Derived Mesenchymal Stromal Cells: A Review from Basic Research to Clinical Applications. Stromal Cells - Struct Funct Ther Implic. 2018 Nov 5

30. Huang L, Zhang C, Gu J, Wu W, Shen Z, Zhou X, et al. A Randomized, Placebo-Controlled Trial of Human Umbilical Cord Blood Mesenchymal Stem Cell Infusion for Children With Cerebral Palsy. Cell Transplant. 2018;27(2):325-34.

31. Wang J, Zeng XX, Cai W, Han ZB, Zhu LY, Liu JY, Xu JX. Safety and efficacy of placenta-derived mesenchymal stem cell treatment for diabetic patients with critical limb ischemia: A pilot study. Experimental and Clinical Endocrinology \& Diabetes. 2021;129(07):542-8.

32. Arutyunyan I, Elchaninov A, Makarov A, Fatkhudinov T. Umbilical Cord as Prospective Source for Mesenchymal Stem Cell-Based Therapy. Stem Cells Int. 2016; 2016.

33. Taghizadeh RR, Cetrulo KJ, Cetrulo CL. Wharton's Jelly stem cells: future clinical applications. Placenta. 2011;32 Suppl 4:S311-315.

34. Matikainen T, Laine J. Placenta-an alternative source of stem cells. Toxicol Appl Pharmacol. 2005;207(2 Suppl):544-9.

35. Zhu H, Xiong Y, Xia Y, Zhang R, Tian D, Wang T, et al. Therapeutic Effects of Human Umbilical CordDerived Mesenchymal Stem Cells in Acute Lung Injury Mice. Sci Rep. 2017;7(1):1-11.

36. Wu M, Zhang R, Zou Q, Chen Y, Zhou M, Li X, et al. Comparison of the Biological Characteristics of Mesenchymal Stem Cells Derived from the Human Placenta and Umbilical Cord. Sci Rep. 2018;8(1):1-9.

37. Leng Z, Zhu R, Hou W, Feng Y, Yang Y, Han Q, et al. Transplantation of ACE2 -Mesenchymal Stem Cells Improves the Outcome of Patients with COVID-19 Pneumonia. Aging Dis. 2020;11:216-28.

38. Hoffmann M, Kleine-Weber H, Krüger N, Müller M, Drosten C, Pöhlmann S. The novel coronavirus 2019 (2019-nCoV) uses the SARS-coronavirus receptor ACE2 and the cellular protease TMPRSS2 for entry into target cells. bioRxiv. 2020;2020.01.31.929042.

39. Zhao Y, Zhao Z, Wang Y, Zhou Y, Ma Y, Zuo W. Single-cell RNA expression profiling of ACE2, the putative receptor of Wuhan 2019-nCov. bioRxiv. 2020;2020.01.26.919985. 
40. Shulla A, Heald-Sargent T, Subramanya G, Zhao J, Perlman S, Gallagher T. A Transmembrane Serine Protease Is Linked to the Severe Acute Respiratory Syndrome Coronavirus Receptor and Activates Virus Entry. J Virol. 2011;85(2):873-82.

41. Berger MJ, Adams SD, Tigges BM, Sprague SL, Wang X-J, Collins DP, et al. Differentiation of umbilical cord blood-derived multilineage progenitor cells into respiratory epithelial cells. Cytotherapy. 2006;8(5):480-7.

42. Wang Y, Zhao S. Placental Tissue and Cord Blood Stem Cells. Morgan \& Claypool. Life Sciences; 2010

43. Gupta N, Su X, Popov B, Lee JW, Serikov V, Matthay MA. Intrapulmonary delivery of bone marrowderived mesenchymal stem cells improves survival and attenuates endotoxin-induced acute lung injury in mice. J Immunol Baltim Md 1950. 2007;179(3):1855-63.

44. Lee JW, Fang X, Gupta N, Serikov V, Matthay MA. Allogeneic human mesenchymal stem cells for treatment of E. coli endotoxin-induced acute lung injury in the ex vivo perfused human lung. Proc Natl Acad Sci U S A. 2009;106(38):16357-62.

45. Lee JW, Gupta N, Serikov V, Matthay MA. Potential application of mesenchymal stem cells in acute lung injury. Expert Opin Biol Ther. 2009;9(10):1259-70.

46. Matthay MA. Therapeutic Potential of Mesenchymal Stromal Cells for Acute Respiratory Distress Syndrome. Ann Am Thorac Soc. 2015;12(Suppl 1):S54-7.

47. ARDS Definition Task Force, Ranieri VM, Rubenfeld GD, Thompson BT, Ferguson ND, Caldwell E, et al. Acute respiratory distress syndrome: the Berlin Definition. JAMA. 2012;307(23):2526-33.

48. Yang K, Wang J, Wu M, Li M, Wang Y, Huang X. Mesenchymal stem cells detect and defend against gammaherpesvirus infection via the cGAS-STING pathway. Scientific reports. 2015;5(1):1-9.

49. Bian P, Ye C, Zheng X, Yang J, Ye W, Wang Y, et al. Mesenchymal stem cells alleviate Japanese encephalitis virus-induced neuroinflammation and mortality. Stem Cell Res Ther. 2017;8(1):38.

50. Chandra PK, Gerlach SL, Wu C, Khurana N, Swientoniewski LT, Abdel-Mageed AB, et al. Mesenchymal stem cells are attracted to latent HIV-1-infected cells and enable virus reactivation via a noncanonical PI3K-NFKB signaling pathway. Sci Rep. 2018;8(1):1-17.

51. Chen J, Hu C, Chen L, Tang L, Zhu Y, Xu X, Chen L, Gao H, Lu X, Yu L, Dai X. Clinical study of mesenchymal stem cell treatment for acute respiratory distress syndrome induced by epidemic influenza A (H7N9) infection: a hint for COVID-19 treatment. Engineering. 2020;6(10):1153-61.

52. Maytawan Thanunchai, Suradej Hongeng, Arunee Thitithanyanont, Mesenchymal Stromal Cells and Viral Infection. Stem Cells International. 2015, 2015

53. Perlman S., Dandekar A.A. Immunopathogenesis of coronavirus infections: implications for SARS. Nat. Rev. Immunol. 2005;5:917-927.

54. Costela-Ruiz VJ, Illescas-Montes R, Puerta-Puerta JM, Ruiz C, Melguizo-Rodríguez L. SARS-CoV-2 infection: The role of cytokines in COVID-19 disease. Cytokine Growth Factor Rev. 2020;54:62-75. 
55. Zhao W, Pi H, Feng W, Li X, Wang J, Liu Y, Jiang Y, Ma J, Xia Y, Wang C, Shao L. Contact or noncontact cocultures of articular chondrocytes with bone marrow mesenchymal stem cells: cell proliferation and differentiation. Chinese Journal of Tissue Engineering Research. 2019;23(1):24.

56. Li Y, Li H, Cao Y, Wu F, Ma W, Wang Y, et al. Placenta-derived mesenchymal stem cells improve airway hyperresponsiveness and inflammation in asthmatic rats by modulating the Th17/ Treg balance. Mol Med Rep. 2017;16(6):8137-45.

57. Li T, Xia M, Gao Y, Chen Y, Xu Y. Human umbilical cord mesenchymal stem cells: an overview of their potential in cell-based therapy. Expert Opin Biol Ther. 2015;15(9):1293-306.

58. I X, Yue S, Luo Z. Mesenchymal stem cells in idiopathic pulmonary fibrosis. Oncotarget. 2017;8(60):102600-16.

59. Sueblinvong V, Loi R, Eisenhauer PL, Bernstein IM, Suratt BT, Spees JL, et al. Derivation of Lung Epithelium from Human Cord Blood-derived Mesenchymal Stem Cells. Am J Respir Crit Care Med. 2008;177(7):701-11.

60. Cao Y, Wu H, Zhai W, Wang Y, Li M, Li M, Yang L, Tian Y, Song Y, Li J, Wang Y, Ding Q, Zhang L, Cai M, Chang Z. A safety consideration of mesenchymal stem cell therapy on COVID-19. Stem Cell Res. 2020;49:102066.

61. Lee JH, Parthiban P, Jin GZ, Knowles JC, Kim HW. Materials roles for promoting angiogenesis in tissue regeneration. Progress in Materials Science. 2021;117:100732.

62. Matute-Bello G, Frevert CW, Martin TR. Animal models of acute lung injury. Am J Physiol Lung Cell Mol Physiol. 2008;295(3):L379-99.

63. Wagner B, Henschler R. Fate of intravenously injected mesenchymal stem cells and significance for clinical application. Adv Biochem Eng Biotechnol. 2013;130:19-37.

64. Tögel $F$, Yang $Y$, Zhang P, Hu Z, Westenfelder $C$. Bioluminescence imaging to monitor the in vivo distribution of administered mesenchymal stem cells in acute kidney injury. Am J Physiol - Ren Physiol. 2008;295(1):F315-21.

65. Schrepfer S, Deuse T, Reichenspurner H, Fischbein MP, Robbins RC, Pelletier MP. Stem cell transplantation: the lung barrier. Transplant Proc. 2007;39(2):573-6.

66. Cardenes N, Aranda-Valderrama P, Carney JP, Sellares Torres J, Alvarez D, Kocydirim E, et al. Cell therapy for ARDS: efficacy of endobronchial versus intravenous administration and biodistribution of MAPCs in a large animal model. BMJ Open Respir Res. 2019;12;6(1):e000308

67. Asmussen S, Ito H, Traber DL, Lee JW, Cox RA, Hawkins HK, et al. Human mesenchymal stem cells reduce the severity of acute lung injury in a sheep model of bacterial pneumonia. Thorax. 2014;69(9):819-25.

68. McAuley DF, Curley GF, Hamid UI, Laffey JG, Abbott J, McKenna DH, et al. Translational Research in Acute Lung Injury and Pulmonary Fibrosis: Clinical grade allogeneic human mesenchymal stem cells restore alveolar fluid clearance in human lungs rejected for transplantation. Am J Physiol - Lung Cell Mol Physiol. 2014;306(9):L809. 
69. Zickri MB, Fadl SGA, Metwally HG. Comparative Study between Intravenous and Intraperitoneal Stem Cell Therapy in Amiodarone Induced Lung Injury in Rat. Int J Stem Cells. 2014;7(1):1-11.

70. Crop MJ, Korevaar SS, de Kuiper R, IJzermans JNM, van Besouw NM, Baan CC, et al. Human mesenchymal stem cells are susceptible to lysis by CD8(+) T cells and NK cells. Cell Transplant. 2011;20(10):1547-59.

71. Guo Z, Chen Y, Luo X, He X, Zhang Y, Wang J. Administration of umbilical cord mesenchymal stem cells in patients with severe COVID-19 pneumonia. Critical Care. 2020;24(1):420.

72. Chen H, Zhang L, He Z, Wang D, Liu L, Zhang W, et al. Systemic administration of human umbilical cord-derived mesenchymal stem cells effectively ameliorates the outcomes of a critically ill elderly patient with COVID-19 with multiple comorbidities: A case report. World Academy of Sciences Journal. 2020;2:2020.

73. Zhang Y., Ding J., Ren S., Wang W., Yang Y., Li S. Intravenous infusion of human umbilical cord Wharton's jelly-derived mesenchymal stem cells as a potential treatment for patients with COVID-19 pneumonia. Stem Cell Res. Ther. 2020;27:207. 11.

74. 31. Peng H., Gong T., Huang X., Sun X., Luo H., Wang W. A synergistic role of convalescent plasma and mesenchymal stem cells in the treatment of severely ill COVID-19 patients: a clinical case report. Stem Cell Res. Ther. 2020;16:291. 11.

75. Sengupta V., Sengupta S., Lazo A., Woods P., Nolan A., Bremer N. Exosomes derived from bone marrow mesenchymal stem cells as treatment for severe COVID-19. Stem Cells Dev. 2020;15:747754. 29.

76. Singh S., Chakravarty T., Chen P., Akhmerov A., Falk J., Friedman O. Allogeneic cardiosphere-derived cells (CAP-1002) in critically ill COVID-19 patients: compassionate-use case series. Basic Res. Cardiol. 2020;12:36. 115.

77. Tenforde MW, Kim SS, Lindsell CJ, Billig Rose E, Shapiro NI, Files DC, Gibbs KW, Erickson HL, Steingrub JS, Smithline HA, Gong MN, Aboodi MS, Exline MC, Henning DJ, Wilson JG, Khan A, Qadir N, Brown SM, Peltan ID, Rice TW, Hager DN, Ginde AA, Stubblefield WB, Patel MM, Self WH, Feldstein LR; IVY Network Investigators; CDC COVID-19 Response Team; IVY Network Investigators. Symptom Duration and Risk Factors for Delayed Return to Usual Health Among Outpatients with COVID-19 in a Multistate Health Care Systems Network - United States, March-June 2020. MMWR Morb Mortal Wkly Rep. 2020;69(30):993-998.

78. Carfi A, Bernabei R, Landi F. Gemelli against COVID-19 post-acute care study group. Persistent symptoms in patients after acute COVID-19. JAMA. 2020;324(6):603-5

79. Nalbandian, A., Sehgal, K., Gupta, A. et al. Post-acute COVID-19 syndrome. Nat Med 27, 601-615 (2021).

80. Kiththiworaphongkich , W. Disease course and temporal changes of chest X-ray findings in COVID-19 positive patients at Phayao hospital. Journal of Nakornping Hospital, 2021;12(1), 149-167.

81. Wang Y, Dong C, Hu Y, Li C, Ren Q, Zhang X, Shi H, Zhou M. Temporal changes of CT findings in 90 patients with COVID-19 pneumonia: a longitudinal study. Radiology. 2020;296(2):E55-64.) 
82. Wang C, Huang P, Wang L, Shen Z, Lin B, Wang Q, Zhao T, Zheng H, Ji W, Gao Y, Xia J. Temporal changes of COVID-19 pneumonia by mass evaluation using CT: a retrospective multi-center study. Annals of Translational Medicine. 2020;8(15).

\section{Figures}

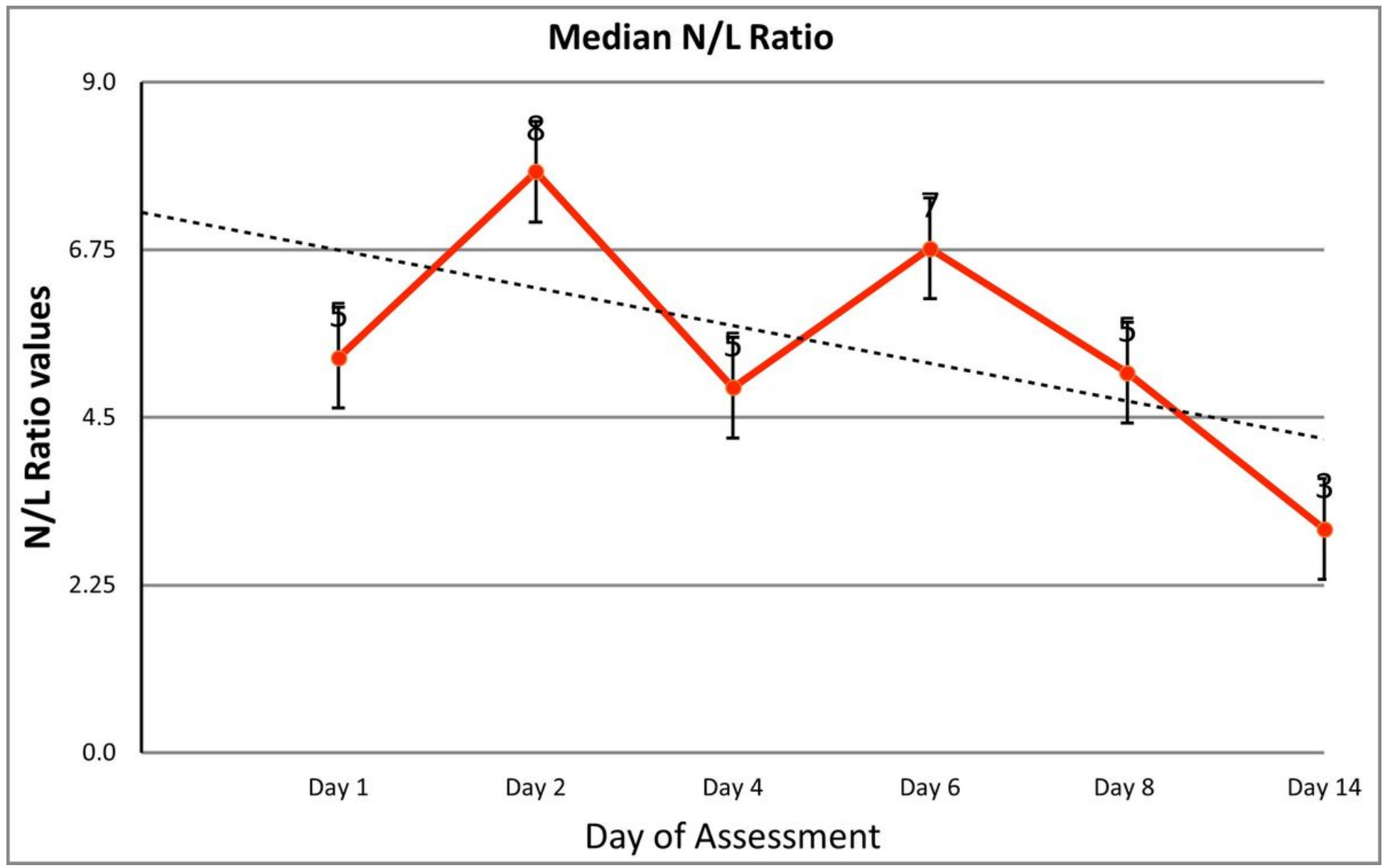

Figure 1

Changes in median Neutrophil-Lymphocyte Ratio after intervention on Day 1, 2, 4, 6, 8 and 14 


\section{Median N/L Ratio}

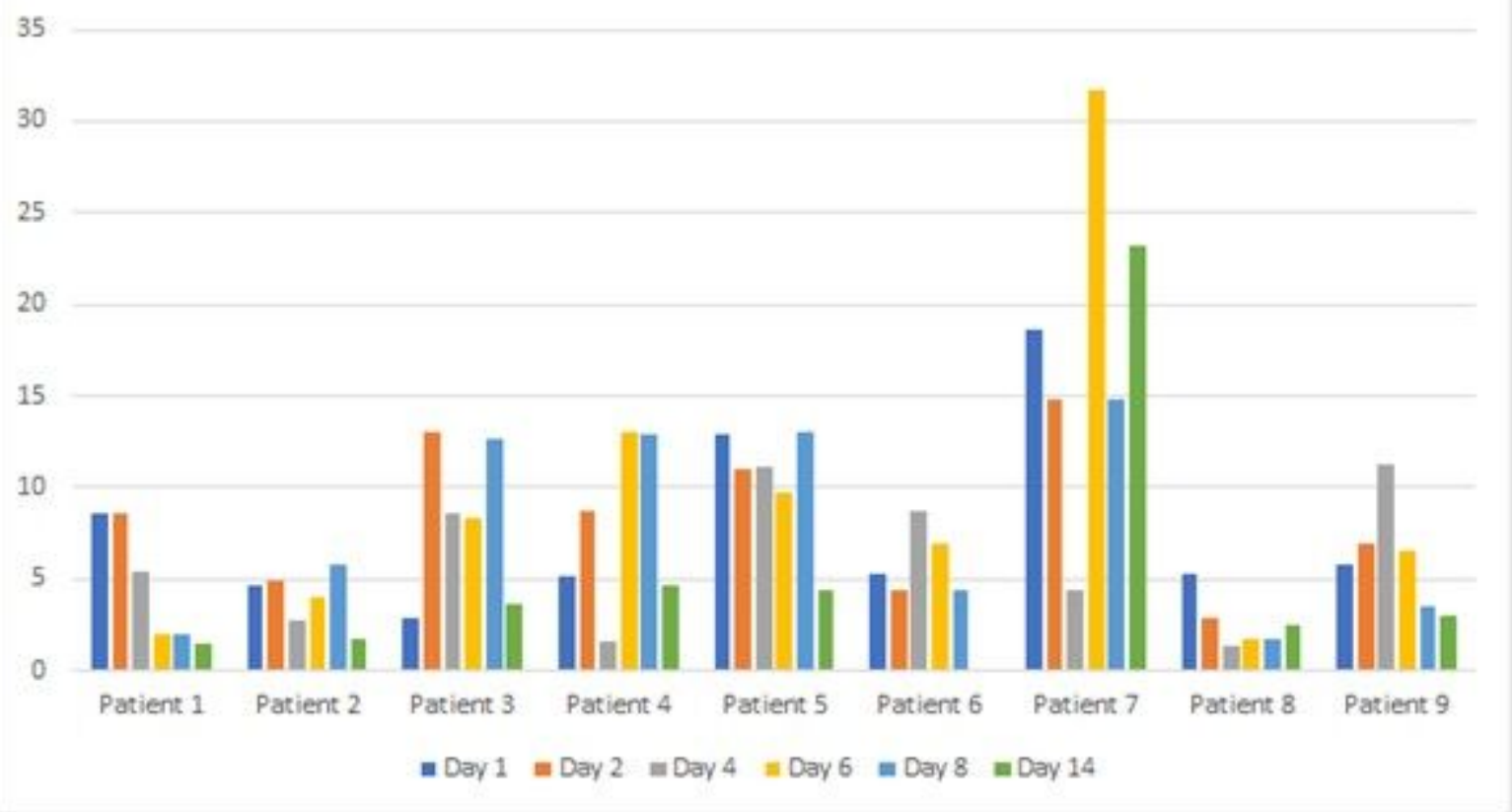

Figure 2

Changes in Neutrophil-Lymphocyte Ratio in each patient after intervention on Day 1, 2, 4, 6, 8 and 14

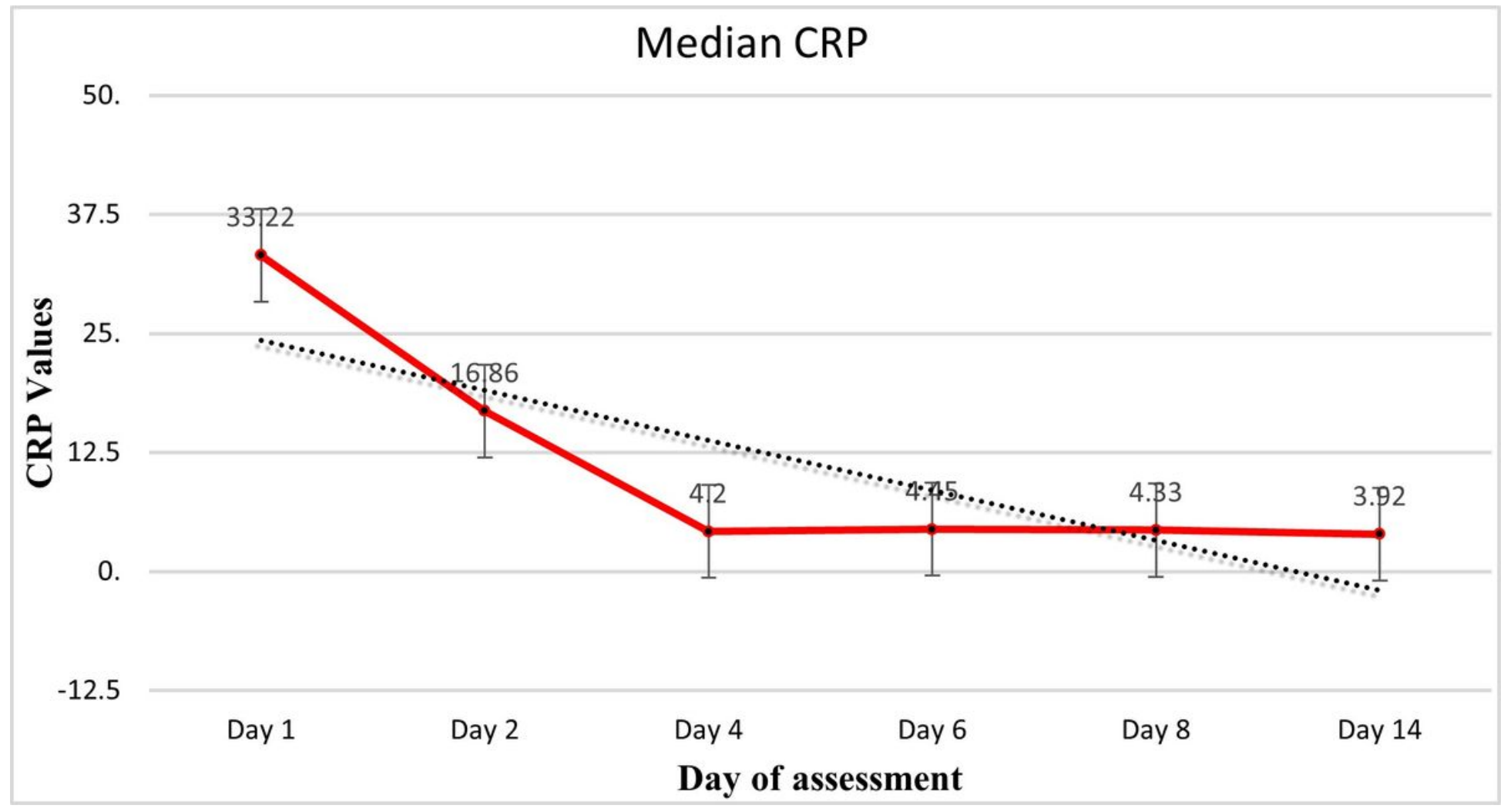

Figure 3

Changes in Median C-reactive protein after intervention on Day 1, 2, 4, 6, 8 and 14 


\section{CRP (Normal values:0-6mg/L)}

90.

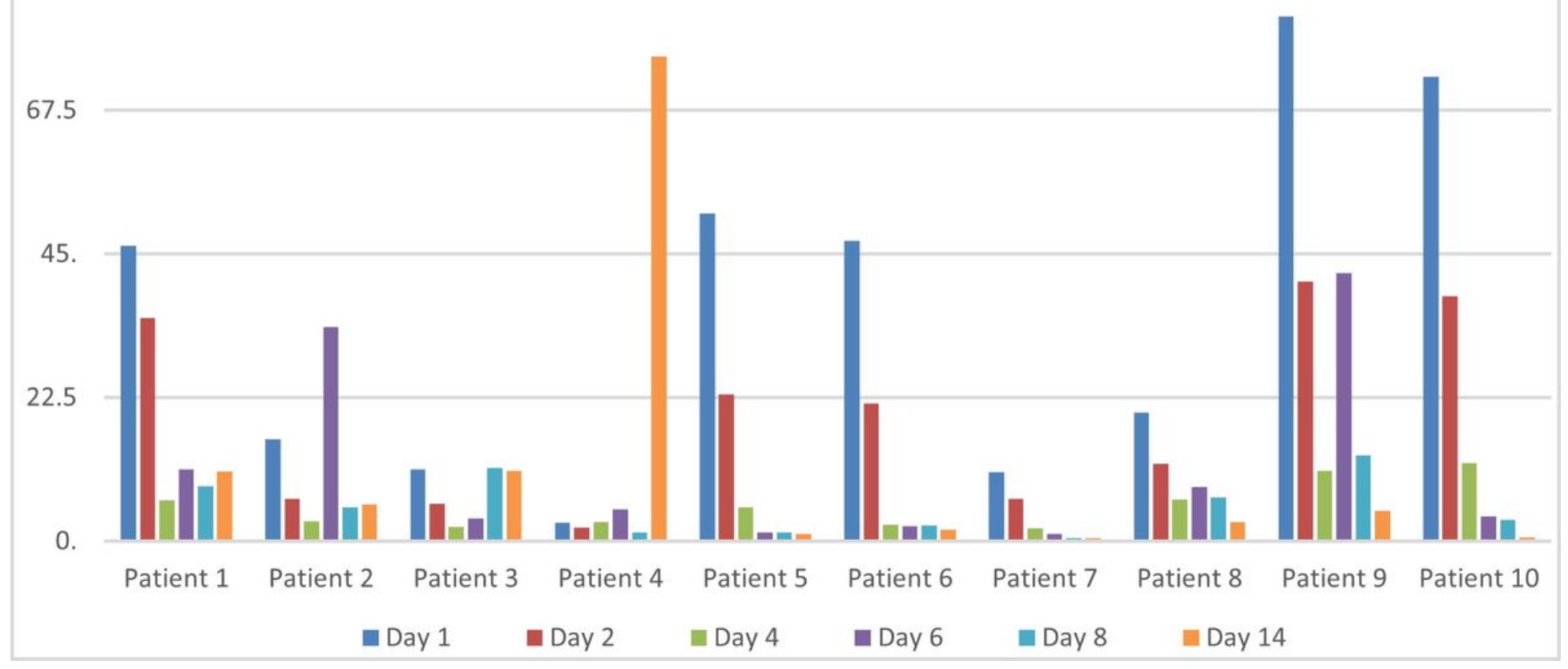

Figure 4

Changes in C-reactive protein levels in each patient after intervention on Day 1, 2, 4, 6, 8 and 14

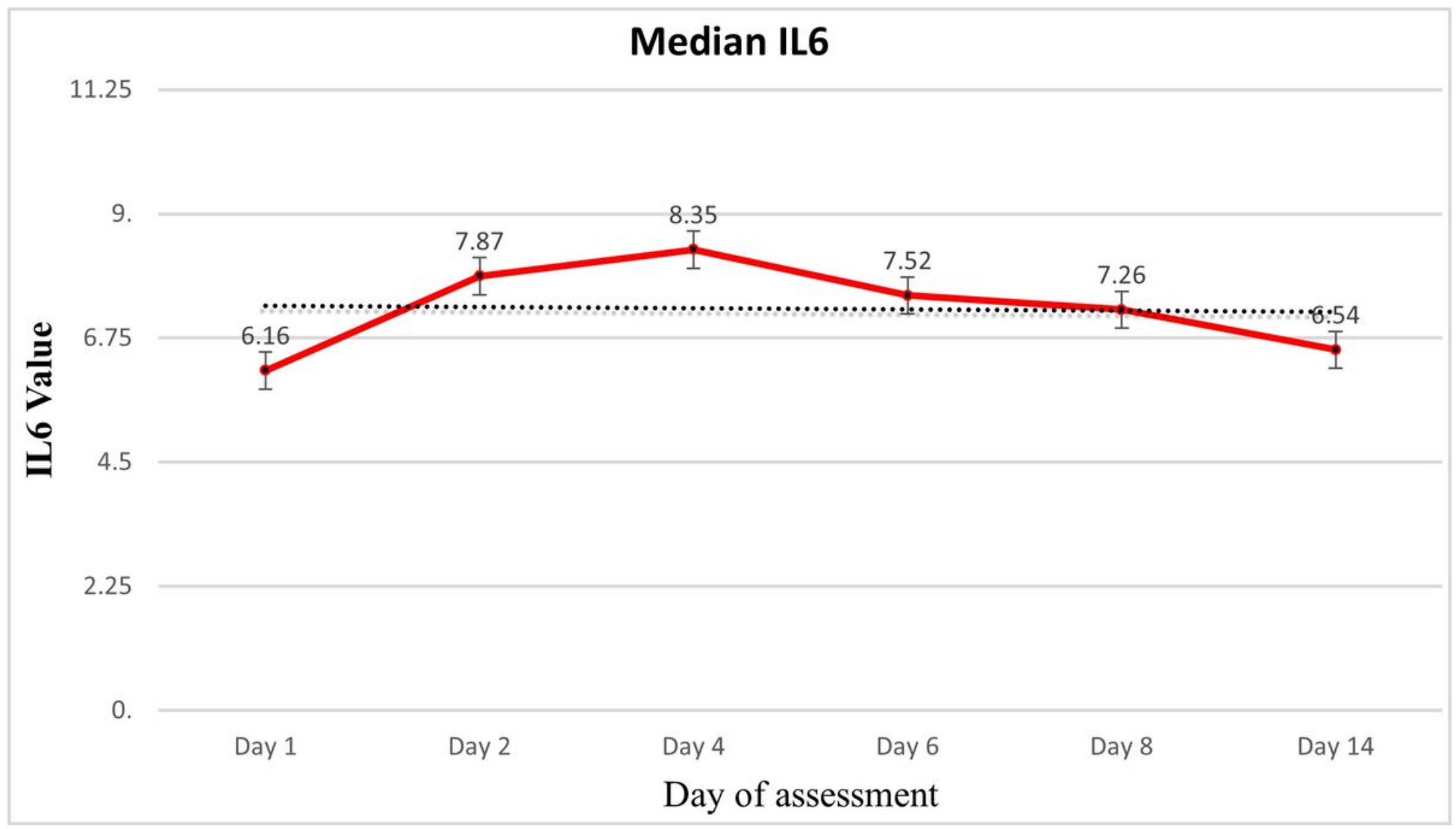


Figure 5

Changes in interleukin 6 levels after intervention on Day 1, 2, 4, 6, 8 and 14

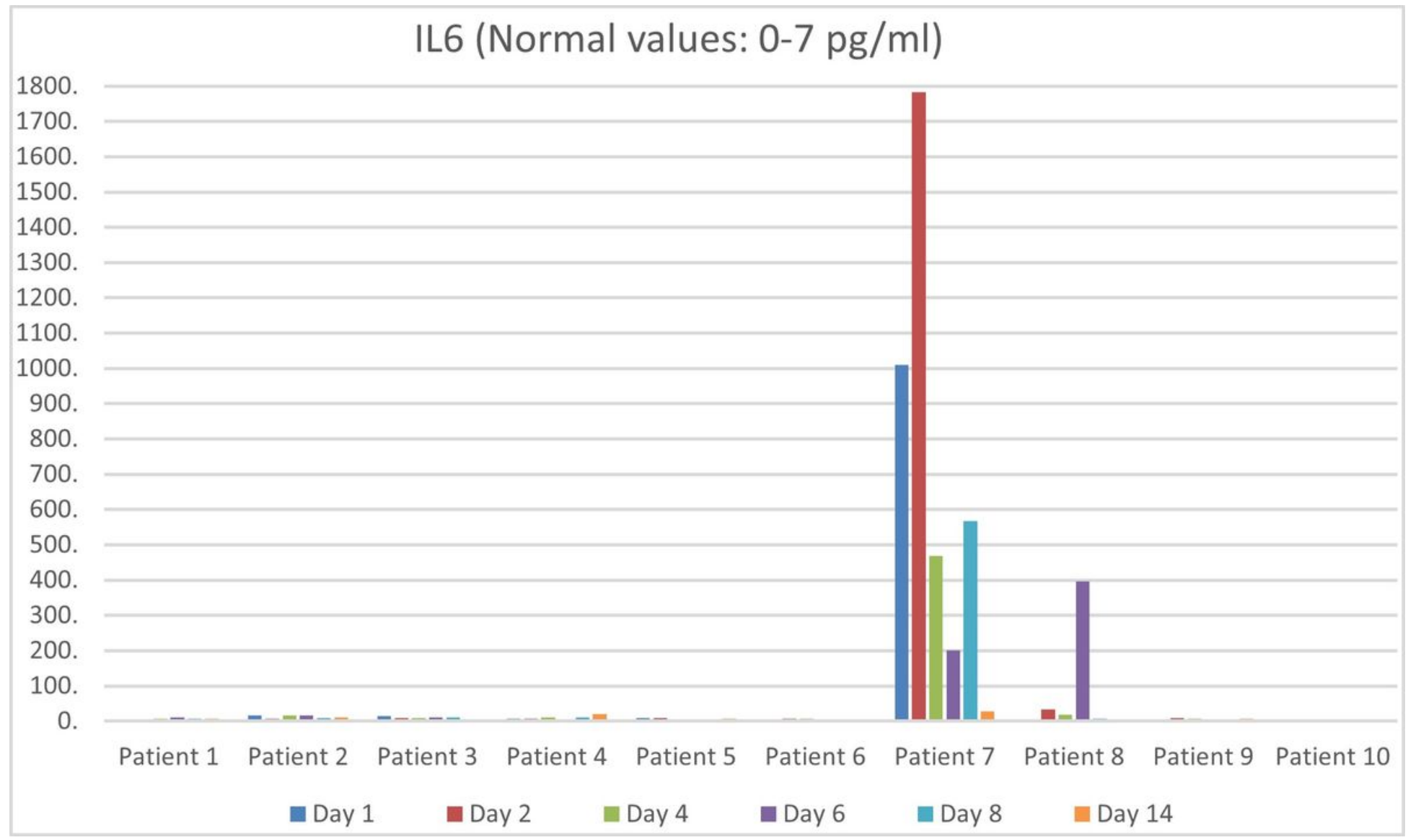

\section{Figure 6}

Changes in IL 6 levels of each patient after intervention on Day 1, 2, 4, 6, 8 and 14 


\section{Median Ferritin}

500.

375.

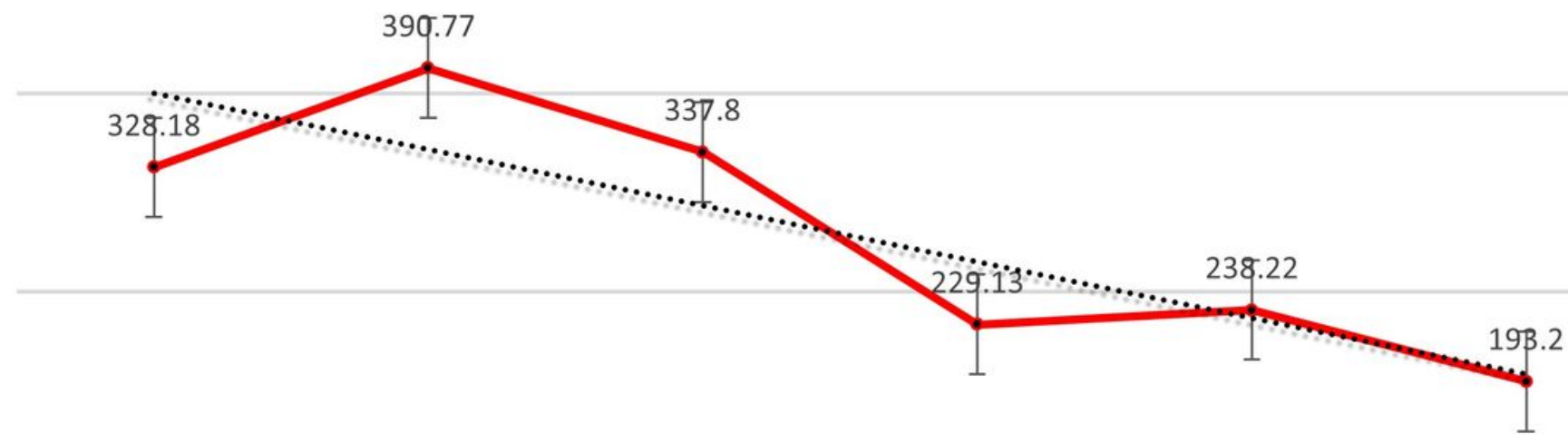

125.

0.

Day 1

Day 2

Day 4

Day 6

Day 8

Day 14

Figure 7

Changes in Levels of blood ferritin after intervention on Day 1, 2, 4, 6, 8 and 14

Ferritin Normal Values $20-300$ ng/mL

1000.

750.

500.

250.

0.

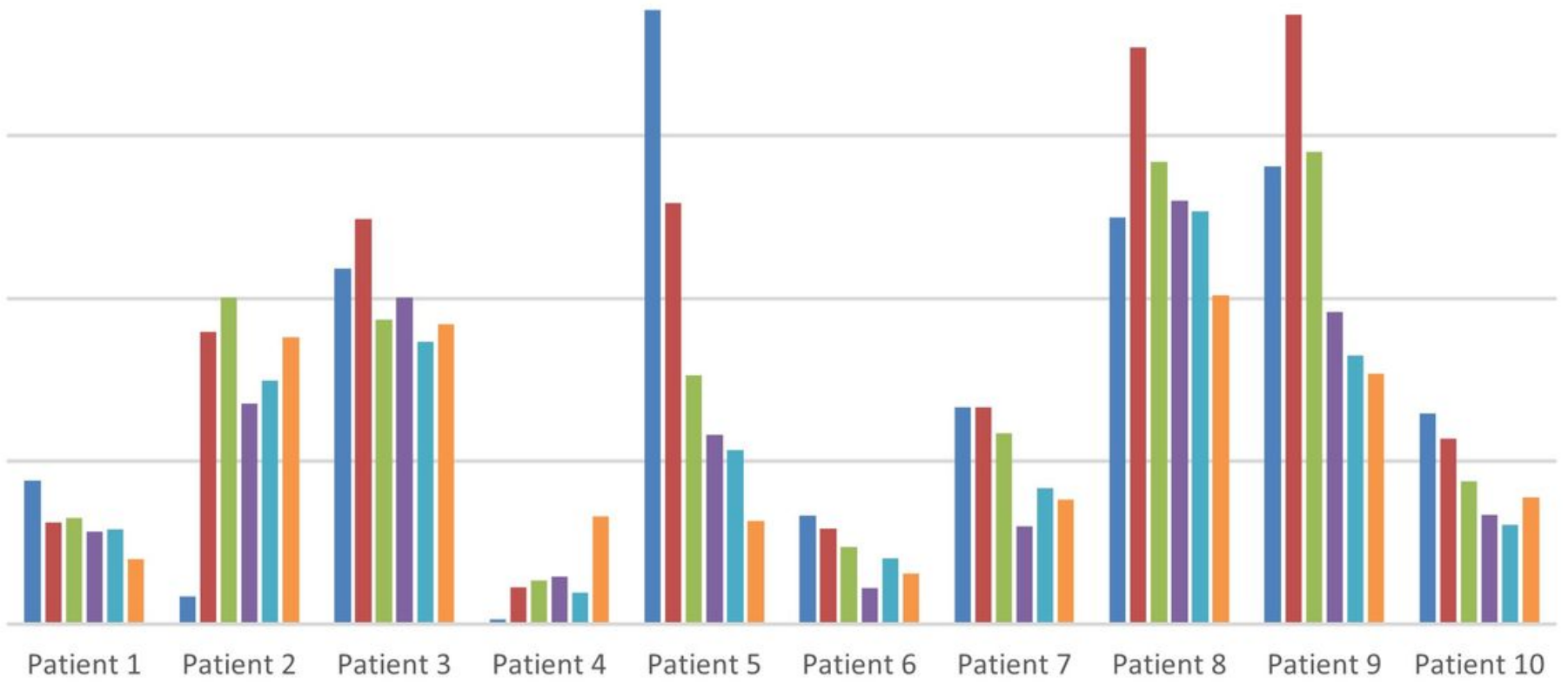

- FerritinDay 1

- FerritinDay 2

- FerritinDay 4

- FerritinDay 6

- FerritinDay 8

nerritinDay 14

Figure 8 
Changes in levels of blood ferritin in each patient after intervention on Day 1, 2, 4, 6, 8 and 14

\section{Median D-Dimer}

0.9

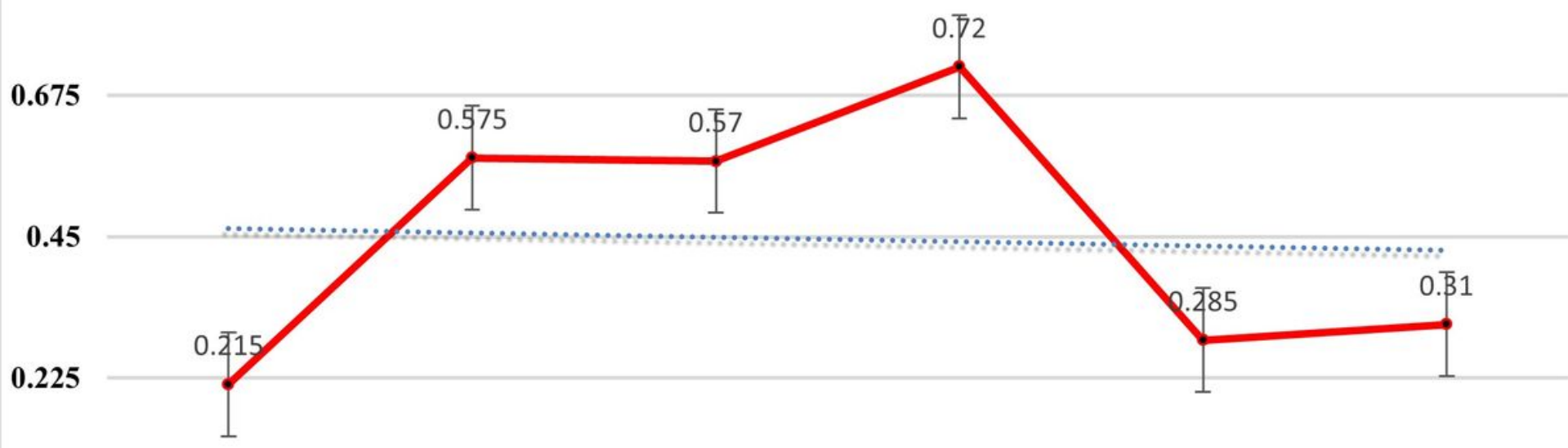

0.
Day 1
Day 2
Day 4
Day 6
Day 8
Day 14

Figure 9

Changes in levels of D-dimer after intervention on Day $1,2,4,6,8$ and 14

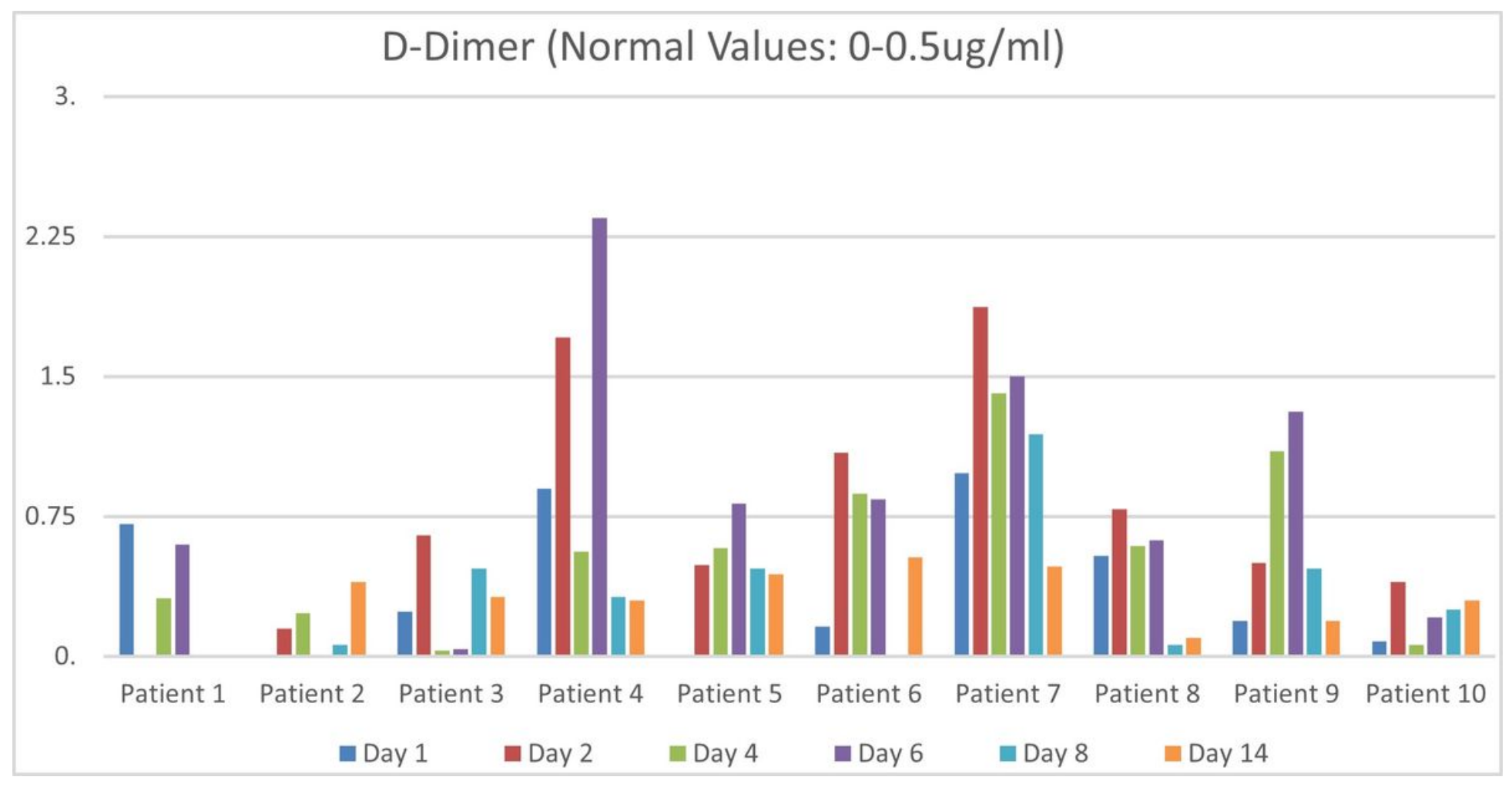

Figure 10

Changes in levels of D-dimer in each patient after intervention on Day 1, 2, 4, 6, 8 and 14 


\section{$\mathrm{SpO} 2 / \mathrm{FiO} 2$}

625.

500.

375.

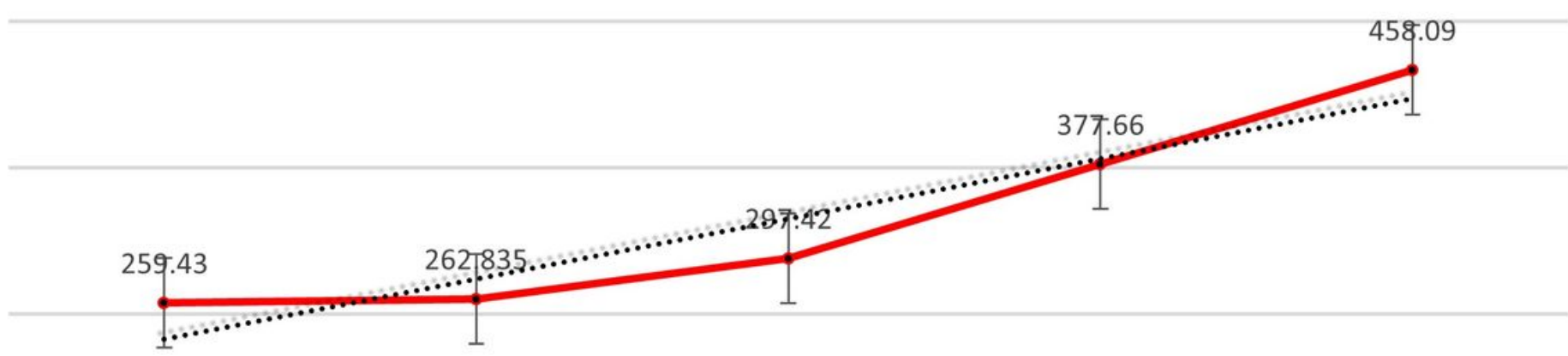

125.

0.

Day 1

Day 2

Day 4

Day 6

Day 8

Figure 11

Changes in the SpO2 / FiO2 index after intervention on Day 1, 2, 4, 6, 8 and 14

Figure 12

Changes in the SpO2 / FiO2 index in each patient after intervention on Day 1, 2, 4, 6, 8 and 14 


\section{$\mathrm{PaO} 2 / \mathrm{FiO} 2$}

500.

375.

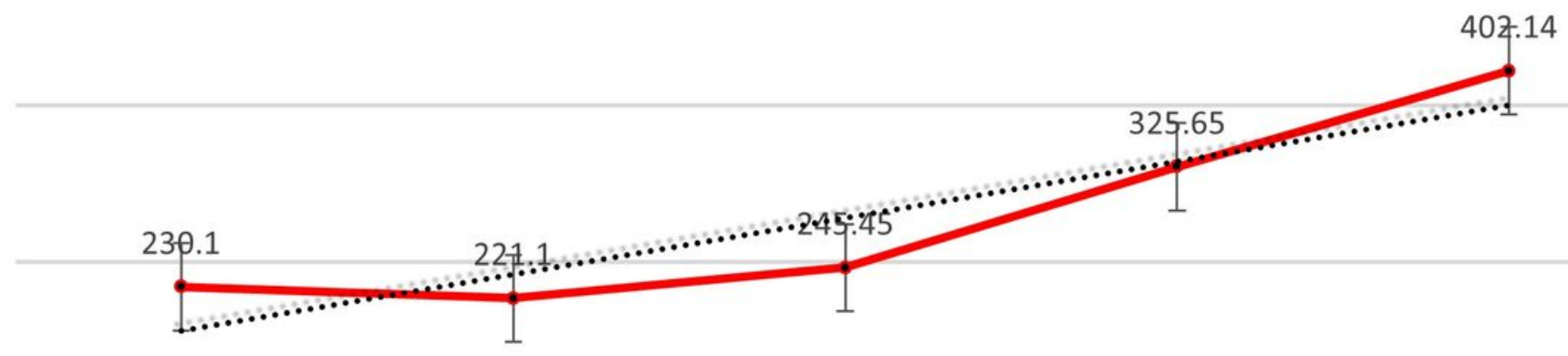

125.

0.

\section{Day 1}

Day 2

Day 4

Day 6

Day 8

Figure 13

Changes in the $\mathrm{PaO} 2$ / FiO2 index after intervention on Day 1, 2, 4, 6, 8 and 14

\section{$\mathrm{PaO} 2 / \mathrm{FiO} 2$}

600.

450.

300.

150.

0 .

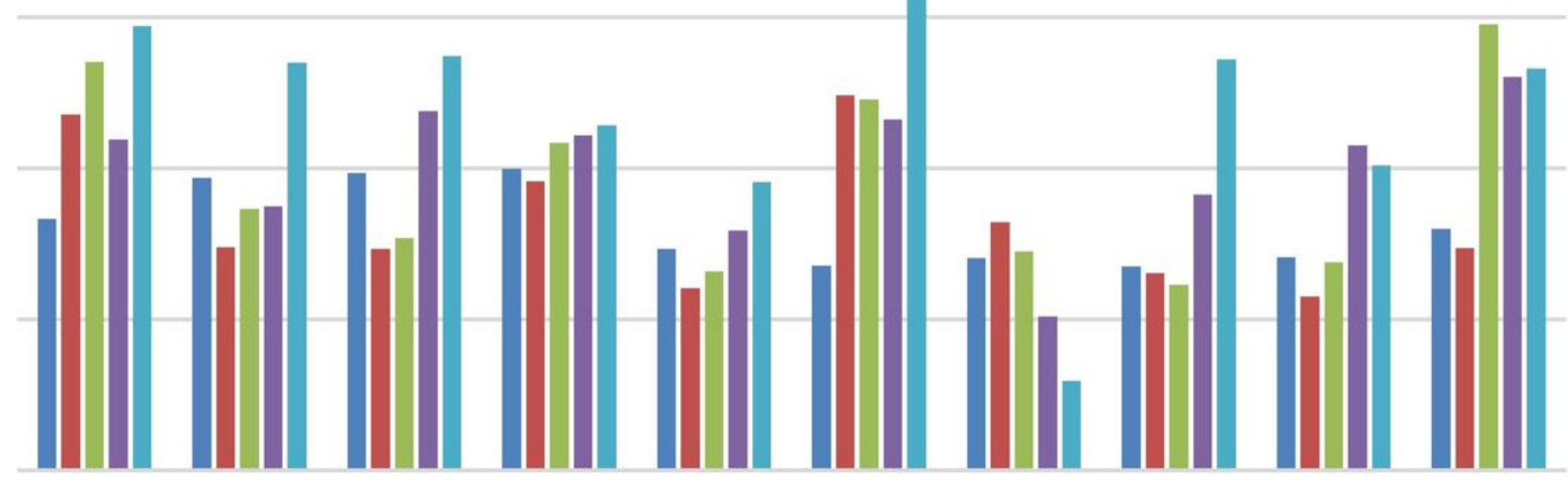

Patient 1 Patient 2 Patient 3 Patient 4 Patient 5 Patient 6 Patient 7 Patient 8 Patient 9 Patient 10 Day 1 Day 2 Day 4 Day 6 Day 8

\section{Figure 14}

Changes in the PaO2 /FiO2 index in each patient after intervention on Day 1, 2, 4, 6, 8 and 14 

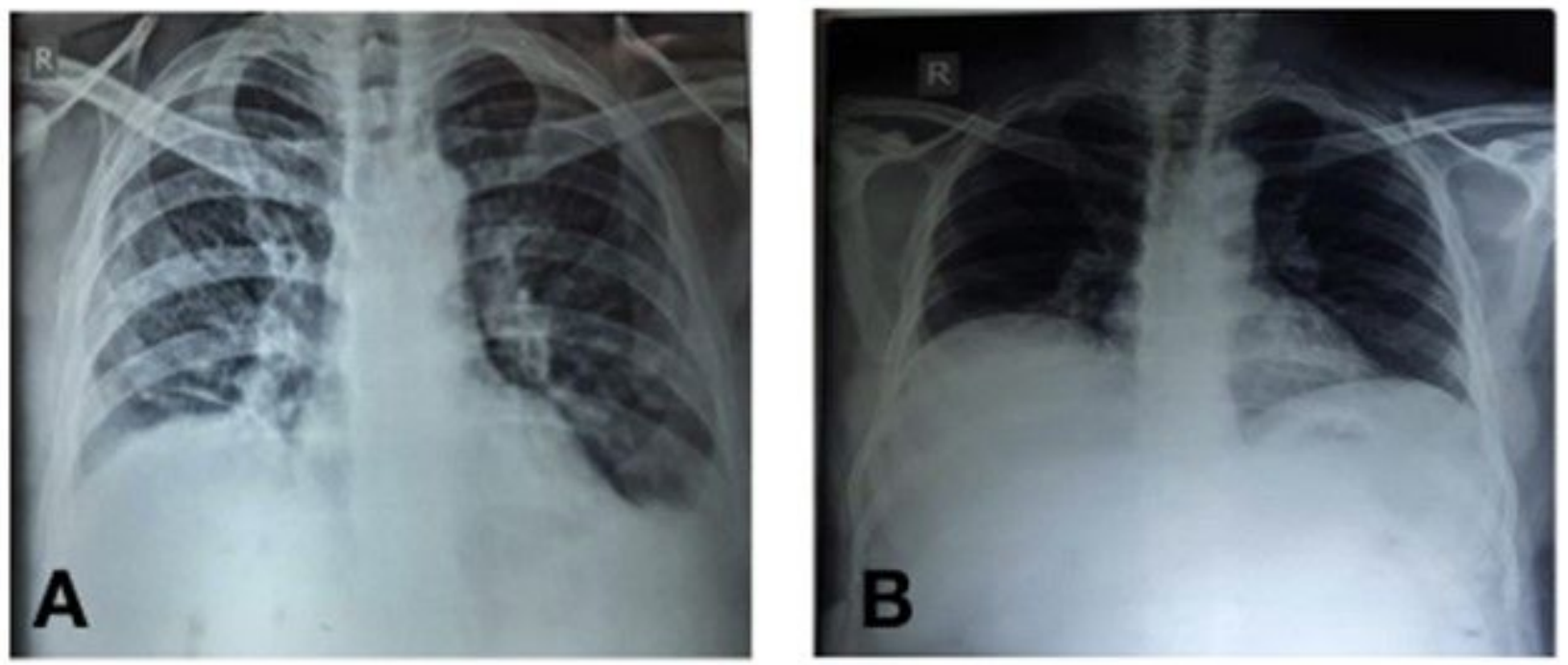

Figure 15

A. Chest radiograph on Day 1 showing homogenous radio opacity in bilateral mid \& lower zones. B. Chest radiograph on Day 14 showing complete resolution of opacities. 

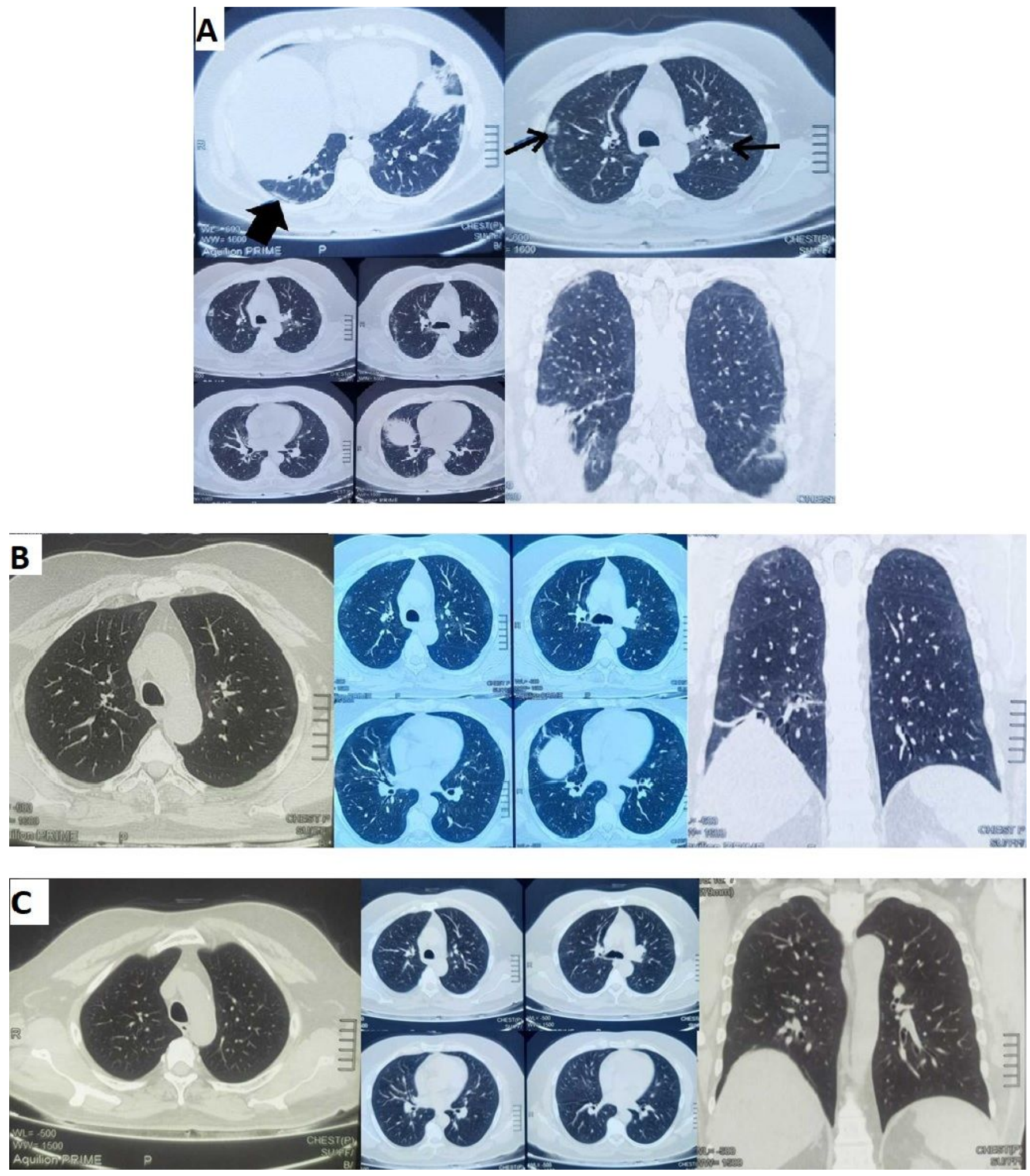

Figure 16

A: Day 1 (before stem cell infusion) - CT severity score 10, HRCT images showing subpleural and bronchocentric ground glass opacities in bilateral upper and lower lobe (shown by arrows) and atelectactic subpleural bands in the lower lobe (shown by a block arrow)

B: Day 7 CT severity score 8 , significant reduction in the ground glass opacities and atelectatic changes 
C: Day 28 CT severity score 4, complete resolution of ground glass opacities, subpleural lines and atelectatic bands 